NBER WORKING PAPER SERIES

\title{
DYNAMIC PRICING IN THE PRESENCE OF ANTIDUMPING POLICY: THEORY AND EVIDENCE
}

\author{
Bruce A. Blonigen \\ Jee-Hyeong Park \\ Working Paper 8477 \\ http://www.nber.org/papers/w8477 \\ NATIONAL BUREAU OF ECONOMIC RESEARCH \\ 1050 Massachusetts Avenue \\ Cambridge, MA 02138 \\ September 2001
}

Preliminary draft. Comments are very welcome. We thank Robert Feenstra, John Kennan, Scott Taylor, and participants of seminars and conference presentations at the University of California-Davis, Dartmouth College, Midwest International Economics Meetings, the $9^{\text {th }}$ International Economics Convention in Seoul, the international workshop "WTO and World Trade II" in Seattle, and University of Wisconsin for helpful comments and suggestions, with special thanks to Michael Knetter, E. Young Song and Robert Staiger for their detailed comments. Blonigen acknowledges support from NSF grant no. 9810706 and a Richard A. Bray Fellowship. The views expressed herein are those of the authors and not necessarily those of the National Bureau of Economic Research.

(C) 2001 by Bruce A. Blonigen and Jee-Hyeong Park. All rights reserved. Short sections of text, not to exceed two paragraphs, may be quoted without explicit permission provided that full credit, including $(\subset$ notice, is given to the source. 
Dynamic Pricing in the Presence of Antidumping Policy: Theory and Evidence

Bruce A. Blonigen and Jee-Hyeong Park

NBER Working Paper No. 8477

September 2001

JEL No. F13, L11

\begin{abstract}
$\underline{\text { ABSTRACT }}$
Antidumping (AD) duties are calculated as the difference between the foreign firm's product price in the export market and some definition of "normal" or "fair" value, often the foreign firm's product price in its own market. Additionally, $\mathrm{AD}$ laws allow for recalculation of these $\mathrm{AD}$ duties over time in what are known as administrative reviews. This paper examines for the first time the resulting dynamic pricing problem of a foreign firm that faces such an $\mathrm{AD}$ trade protection policy in its export market. When $\mathrm{AD}$ duties are certain for any dumping that occurs, we obtain the surprising result that dumping and $\mathrm{AD}$ duties should increase over time toward a stationary equilibrium value. Adding uncertainties prevalent in $\mathrm{AD}$ enforcement into our analysis changes these conclusions substantially and leads to more realistic testable implications. Firms with ex ante expectations that the probability of AD enforcement is low, or with expectations that the probability of a termination/VER (instead of AD duties) is high, will decrease their dumping and $\mathrm{AD}$ duties over time in the administrative review process once they face $\mathrm{AD}$ duties. Using detailed data from U.S. AD investigations filed from 1980-1995, we find evidence consistent with these hypotheses stemming from our analysis with uncertain $\mathrm{AD}$ enforcement and provide empirical evidence consistent with James Anderson's domino dumping hypothesis.
\end{abstract}

Bruce A. Blonigen

Department of Economics

University of Oregon

Eugene, OR 97403-1285

and NBER

Tel: 541-346-4680

Fax: 541-346-1243

Email: bruceb@oregon.uoregon.edu
Jee-Hyeong Park

Department of Economics

Wayne State University

Detroit, MI 48202

Tel: 313-577-2693

Fax: 313-577-9564

jhpark@econ.wayne.edu 


\section{Introduction}

Recent research on antidumping (AD) protection policies has revealed that the institutional structure surrounding the determination and administration of $\mathrm{AD}$ duties makes analysis of this form of trade policy quite interesting and complicated. On the surface, AD duties are simple ad valorem tariffs, intended to reflect the extent to which the foreign firm was dumping in the export destination market. The calculated degree of dumping (or dumping "margin") is the difference between a "normal" or "fair" value for the product and the price it is charging in the export market, and there is a positive dumping margin any time the export price is below the "normal" value. The U.S. Department of Commerce (USDOC) primarily uses the price charged by the foreign firm in its own market as the estimate of "normal" value in dumping calculations. In addition, after an $\mathrm{AD}$ duty comes into place there is the potential for continuous recalculation of the $\mathrm{AD}$ duty over time in what are called administrative reviews. These administrative reviews occur at the request of the foreign firm or other interested parties and, in fact, the majority of U.S. AD duties are reviewed at least once subsequent to a case. The method of $\mathrm{AD}$ duty calculation and administrative review process presents a foreign firm with a dynamic pricing problem that has not been explored before and will be the focus of this paper.

While previous research has not considered this dynamic pricing problem, there have been important examinations of how the structure of $\mathrm{AD}$ investigations affects economic outcomes, including price determination. Staiger and Wolak (1994) and Krupp and Pollard (1996) focus on how investigation "events" (i.e., the filing of the petition, public findings of the USDOC, terminations, etc.) affect import and pricing behavior by foreign firms. Staiger and Wolak focus mainly on import volume and price changes during U.S. AD investigations filed from 1980-1986. They find that changes in prices and import volumes during the investigation depend on whether the domestic industry has filed the case to merely harass the foreign firm (they call these domestic petitioners "process" filers) or to gain actual trade protection ("outcome" filers). To the extent that they examine changes in variables after the investigation, they do not consider the administrative review process. Krupp and Pollard use detailed data on chemical products subject to U.S. AD investigations to focus on changes in import volumes due to investigation events, as well as eventual AD duties. DeVault (1996) examines data on the changes in U.S. AD duties from the administrative review process. His empirical work uncovers factors that lead to lower $\mathrm{AD}$ duties over time, but he does not integrate these observations 
within a formal theoretical framework. Finally, Blonigen and Haynes (forthcoming) examine pass-through of exchange rates and $\mathrm{AD}$ duties to U.S. import prices for products involved in U.S. $\mathrm{AD}$ investigations. They present a one-period model of pricing for a firm subject to an AD duty to motivate their empirical work, which finds that because of the way in which AD duties are recalculated in U.S. administrative reviews, pass-through of the $\mathrm{AD}$ duty is more than complete and exchange rate pass-through is substantially altered for their sample of Canadian steel products.

This paper's contribution is to more seriously consider the dynamic pricing problem firms face in the presence of $\mathrm{AD}$ investigations and duties. We first set up a formal theoretical model and then use data on $\mathrm{AD}$ duty changes from U.S. administrative reviews to test some of the model's implications. In the model, a foreign firm is solving a dynamic optimization problem, where the current period price (p) affects the AD duty in the next period $\left(\mathrm{T}_{+1}\right) .{ }^{1}$ Specifically, the lower the current period price is relative to the fair value of the product $\left(\mathrm{p}^{\mathrm{f}}\right)$, the higher the next period $\mathrm{AD}$ duty $\left(\mathrm{T}_{+1}=\mathrm{p}^{\mathrm{f}} / \mathrm{p}\right)$ will be. Given that the foreign firm has a static incentive to dump its product (the static profit maximizing price is less than the fair value), the firm needs to balance the loss in the current period from setting price higher than its static optimal against the gains in the future discounted payoff from having a lower AD duty in the next period.

Under certain enforcement of $\mathrm{AD}$ policy, the dynamic programming analysis yields a surprising result with respect to the optimal pricing path. When a foreign firm dumps (setting its price lower than the fair value) in the initial period, then the firm will dump more over time (setting the price lower over time) until the price reaches a steady state value. Dumping duties will increase (or at least never decrease) through the review process! Knowing how an increase in the $\mathrm{AD}$ duty affects the balance between the loss in the current profit and the gain in the future discounted profit associated with current pricing is the key to understanding this result. In particular, when the $\mathrm{AD}$ duty increases, the rate of current-profit loss associated with pricing higher than the static optimal price increases, implying higher costs of reducing the dumping margin for a higher current $\mathrm{AD}$ duty. Thus, once a firm dumps in the initial period free of any AD duty, the firm will face a steeper trade-off between the current profit loss and the future gain

\footnotetext{
${ }^{1}$ Note that this (one-period) lag in adjusting the $\mathrm{AD}$ duty is crucial in raising the "dynamic" pricing issue. This is because instantaneous adjustment in the AD duty will simply set the consumer price as fixed at the "fair value", regardless of foreign firms' pricing (below the fair value), and, thus, eliminates the incentive to dump. As discussed in Section 2, it is reasonable to assume that there exist significant lags in adjusting AD duties, given the practices of AD policy.
} 
with an $\mathrm{AD}$ duty being imposed in the next period, inducing the firm to choose a price that is at least as low as the initial price. As the same process continues in the following periods, the foreign firm will lower its price over time toward a stationary equilibrium value, implying a rising $\mathrm{AD}$ duty through the review process. This process may even lead to greater levels of dumping than when such policy is absent, thus AD policy with lagged administrative review process can perversely contribute to more aggressive dumping behaviors. ${ }^{2}$ Firms with high enough discount factors will follow this path of increasing dumping, whereas firms with relatively low discount factors will never dump, despite economic conditions that make dumping optimal in absence of the AD policy.

While the benchmark case of certain AD enforcement is important for establishing basic features of our model, it is unlikely that enforcement of AD policy is certain. ${ }^{3}$ In our U.S. data of $\mathrm{AD}$ cases from 1980 through $1995,41 \%$ of the $\mathrm{AD}$ cases were ruled affirmative, $48 \%$ negative and $11 \%$ were terminated because of a publicly-announced settlement (often a VER). In addition, while the benchmark case predicts rising $\mathrm{AD}$ duties over time after the initial $\mathrm{AD}$ duty is imposed, the data reveal that the majority of changes in $\mathrm{AD}$ duties during the administrative review process are declines, not increases.

To analyze dynamic pricing behavior with uncertain $\mathrm{AD}$ enforcement, we modify the model so that foreign firms have ex ante expected probabilities of the possible AD case outcomes: Affirmative with AD duties, negative, or termination with a settlement such as a VER. With this uncertain enforcement, our analysis shows that the foreign firm may reduce the AD duty through the administrative review process (setting higher price over time once the firm needs to pay the dumping duties) when the probability of getting the initial AD duty is low enough. We can explain this result as follows. As the probability of getting the initial AD duty becomes smaller, the foreign firm has an incentive to set its price closer to its static optimum. If

\footnotetext{
${ }^{2}$ Section 3.2 provides a numerical example of this case. Previous papers, including Anderson (1992;1993) and Blonigen and Ohno (1998), also show how the mere presence of AD policy can lead to greater levels of dumping than when $\mathrm{AD}$ policy is absent. In contrast to these earlier studies, where strategic incentives for the foreign and domestic firms to use $\mathrm{AD}$ policy as means of achieving anti-competitive outcome drive this kind of dumping behavior, our analysis shows that the dynamic structure of $\mathrm{AD}$ policy itself may induce the foreign firms to excessive dumping over time even in the absence of any strategic incentives.

${ }^{3}$ One important exception, suggested by Robert Feenstra, was the Trigger Price Mechanism (TPM) adopted by the U.S. with respect to steel products in the late 1970's. Under the TPM, foreign firms automatically faced duties whenever their price fell below a trigger level, which fits our model of certain enforcement well. The program was unsuccessful due to the problems of calculating trigger price adjustments due to exchange rate movements (Eichengreen and van den Ven, 1984), thus making it difficult to compare pricing behavior by firms under the TPM with our model's predictions.
} 
it finds itself subject to paying an $\mathrm{AD}$ duty despite its low probability, the initial dumping price can be lower than the stationary equilibrium price under certain enforcement (note that certain enforcement is assumed in the administrative review process). Thus, the foreign firm will set its price higher over time until the price reaches the stationary value, implying reduction of $A D$ duties through the review process. We also show that when firms believe greater dumping will lead to greater benefits under a terminated/VER outcome (as in Anderson, 1992 and 1993) a high probability of a terminated/VER agreement will lead to AD duty reductions in the event that the firm receives an affirmative outcome. ${ }^{4}$

The latter half of the paper tests the hypotheses from our model of dynamic pricing under uncertain $\mathrm{AD}$ enforcement that links the ex ante probabilities of case outcomes with the reduction in $\mathrm{AD}$ duties through the review process. The empirical analysis adopts a two-step estimation method. We first estimate determinants of the probabilities of AD case outcomes. We then use the parameter estimates to form ex ante outcome probabilities and estimate the effect of these ex ante probabilities on changes in $\mathrm{AD}$ duties in the administrative review process after the initial $\mathrm{AD}$ duty is imposed. Using a sample of all firm-product combinations subject to U.S. affirmative $\mathrm{AD}$ decisions and $\mathrm{AD}$ duties for cases filed between 1980 and 1995, the empirical results support the hypotheses. Consistent with our theory, we find that a lower $e x$ ante affirmative probability leads to significantly greater ex post reductions in the $\mathrm{AD}$ duty in the administrative review process. We also find that a higher ex ante probability of TER leads to significantly greater ex post reduction in AD duties, which is consistent with Anderson's $(1992 ; 1993)$ "domino dumping" phenomenon.

The rest of the paper proceeds as follows. The next section provides some relevant details of U.S. AD trade protection and the administrative review process. Section 3 provides formal dynamic pricing models and our main propositions. Section 4 then describes our empirical analysis and a final section concludes.

\section{Salient Features of U.S. AD Law and Administration.}

This section provides a brief overview of the relevant details connected with U.S. AD investigations and administrative reviews. The U.S. AD laws are administered by the USDOC

\footnotetext{
${ }^{4}$ Anderson (1992;1993) shows that if an agreement after termination takes the form of a VER where more export licenses are given to a foreign firm with higher market share, then foreign firms will more aggressively dump to
} 
and U.S. International Trade Commission (USITC), each with distinct roles in the process. When an $\mathrm{AD}$ petition is filed, the USDOC determines whether the subject product is being sold at "less than fair value" in the United States. In contrast, the USITC determines whether the relevant U.S. domestic industry has been materially injured, or is threatened with material injury, by reason of the imports subject to its investigation.

The calculation of the dumping margin by the USDOC is usually not straightforward and revolves around how the USDOC measures what should be the "fair value" of the product sold in the United States. Selling a product in the United States at less than "fair value" is the definition of dumping and the difference between the U.S. price and "fair value" is the dumping margin. In theory, the USDOC defines "fair value" as the exporting firm's price for the same product in its own home market. However, if the firm's home market sales are deemed inadequate, then the USDOC may base "fair value" on the exporting firm's prices in third country markets or on a constructed value for the product using manufacturing costs, selling, general and administrative costs, profits and packaging costs. These calculations obviously involve highly detailed and confidential data on the transactions of the investigated firm, which are requested by USDOC from the investigated firm. If the investigated firm does not comply sufficiently, the USDOC will turn to using the "best information available," which is often information supplied by the U.S. firms that filed the petition.

If an affirmative preliminary determination is made by both the USDOC and the USITC (which may take up to 160 days), then the importer must post a cash deposit, a bond or other security for each entry equal to the preliminary margin determined by the USDOC. This requirement stays in effect until either the USDOC or the USITC makes a negative final determination, which may take another 120 days. If an affirmative final determination is made by both the USITC and USDOC, then USDOC issues an AD order to levy a duty equal to the estimated dumping margin on the subject product.

When a subject foreign product enters the United States, the importer must pay Customs a cash deposit equal to the margin times the value of the subject product. However, these cash deposits do not necessarily represent the final amount of duties to be assessed on the subject imports. Rather, the margin determined in USDOC's final investigation is only used as a basis for estimating the duty liability of the importer. The actual liability of the importer may be

compete for market share. 
determined in subsequent years by the USDOC. Before 1984, this was accomplished by automatic yearly administrative reviews by the USDOC. However, since 1984, such reviews have become voluntary; that is, unless an interested party requests a review, the duties assessed are those found in USDOC's final determination (or most recent administrative review). An administrative review serves two purposes. First, it adjusts the margin on subject imports to reflect changes in the difference between the foreign firm's U.S. price and the fair value so that the importer pays an adjusted cash deposit based on the reviewed margin until the next administrative review. Second, it makes AD duties retroactive: If a review determines that the margin during the review period is different from the previous margin used as a basis for the importer's cash deposit, a bill (or refund) in the amount of the difference plus interest is assessed (or rebated).

\section{Model of Dynamic Pricing in the Presence of AD Policy.}

This section develops models of dynamic pricing of a foreign firm in the presence of AD policy described in the preceding section. We will first analyze the benchmark case where the AD policy is enforced with certainty and then analyze the case of uncertain AD enforcement. While we think the implications of the benchmark model may be unrealistic for the large part of pricing behavior we observe with respect to U.S. AD cases, it establishes a number of important features of the model that are important for understanding the case of uncertain AD enforcement.

\subsection{Benchmark Model: Certain AD Enforcement.}

We assume that a foreign firm may sell its products both in foreign and domestic markets and these markets are separated from each other so that price discrimination is possible across the markets. However, when the foreign firm chooses its export price in the domestic market, p, lower than its price in its own foreign market, $p^{f}$, the foreign firm faces an AD duty, $T(\geq 1)$ such that $\mathrm{pT}=\mathrm{p}^{\mathrm{f}}$ in the domestic market. ${ }^{5}$ When the foreign firm changes $\mathrm{p}$ or $\mathrm{p}^{\mathrm{f}}$, this AD duty is subject to change through administrative review process, according to $\mathrm{pT}=\mathrm{p}^{\mathrm{f}}$.

\footnotetext{
${ }^{5}$ Once a product is subject to a AD duty, it is not the foreign exporter but the domestic importer who is supposed to pay the $\mathrm{AD}$ duty in practice, potentially creating a conflict of interests among them toward pricing decision, thus a dynamic game to be played between them. However, we do not analyze this issue in the following analysis, by assuming away the existence of the domestic importer who has autonomy in setting consumer price, or alternatively by assuming that the foreign exporter pursues joint profit maximization with the domestic importer.
} 
As the initial dumping determination and the following administrative review are far from instantaneous to changes in the prices, the foreign firm faces a dynamic pricing problem. To analyze this problem, we use an infinite horizon model in which the consumers' tastes are the same in each period. For simplicity, we assume that the change in the AD duty lags one period to changes in the price, $T_{i}=p_{i-1}^{f} / p_{i-1}$ where the subscripts $i$ and $i-1$ denote period $i$ and period $i-1$, respectively, with $T_{0}=1$ (the initial period is free from dumping duties). In addition, we set $\mathrm{p}_{\mathrm{i}-1}^{\mathrm{f}}=\mathrm{p}_{0}^{\mathrm{f}}(>0)$ for all $\mathrm{i} \geq 1$ in determining $\mathrm{T}_{\mathrm{i}}$, because there are compelling reasons and empirical evidence that the overwhelming part of the price change affecting the dumping duties in the review process occurs with the domestic (U.S.) price, not the foreign price. ${ }^{6}$

Let $\mathrm{c}$ be the foreign firm's constant marginal production cost and $\mathrm{q}\left(\mathrm{p}^{\mathrm{c}}\right)$ be its per-period domestic market demand function with $\mathrm{p}^{\mathrm{c}}(=\mathrm{p} \cdot \mathrm{T})$ representing the consumer price. ${ }^{7}$ Then, the discounted profit from the domestic market for the foreign firm in period $\mathrm{k}$ is given by

$$
\sum_{i=0}^{\infty} \delta^{i}\left(p_{k+i}-c\right) \cdot q\left(p_{k+i} \cdot T_{k+i}\left(p_{k+i-1}\right)\right)
$$

where $\delta \in(0,1)$ is the discount factor, $\mathrm{T}_{\mathrm{k}+\mathrm{i}}\left(\mathrm{p}_{\mathrm{k}+\mathrm{i}-1}\right)=\mathrm{p}_{0}^{\mathrm{f}} / \mathrm{p}_{\mathrm{k}+\mathrm{i}-1}$ if $0<\mathrm{p}_{\mathrm{k}+\mathrm{i}-1} \leq \mathrm{p}_{0}^{\mathrm{f}}, \mathrm{T}_{\mathrm{k}+\mathrm{i}}\left(\mathrm{p}_{\mathrm{k}+\mathrm{i}-1}\right)=1$ if $\mathrm{p}_{\mathrm{k}+\mathrm{i}-1}>\mathrm{p}_{0}^{\mathrm{f}}$, and $\mathrm{T}_{\mathrm{k}+\mathrm{i}}\left(\mathrm{p}_{\mathrm{k}+\mathrm{i}-1}\right)=\infty$ if $\mathrm{p}_{\mathrm{k}+\mathrm{i}-1}=0$, meaning that the imports will be prohibited from $\mathrm{k}+1$ period on. ${ }^{8}$

\footnotetext{
${ }^{6}$ As Gallaway et al. (pp. 219-220) discuss, the USDOC has wide discretion to disallow a foreign firm's prices in its own market when determining "normal" value, either deeming them as "below cost", or by finding insufficient sales and turning to a constructed cost measure or prices to a third market. This makes the strategy of reducing the AD duty by lowering the price in the foreign market tenuous at best, and limited empirical evidence shows that foreign firms reduce $\mathrm{AD}$ duties primarily through increases in the price to the home market, not decreases in the foreign price.

${ }^{7}$ We do not analyze strategic interactions between firms in setting prices, focusing on how the structure of AD policy influences a foreign firm's dynamic pricing (dumping) behavior in the domestic market. This simple demand function can be considered as an individual firm's demand in a monopolistically competitive industry. One may pursue an alternative path toward modeling oligopoly firms and analyzing their dynamic pricing interactions in the presence of $\mathrm{AD}$ policy, but we do not pursue this avenue in this paper.

${ }^{8}$ As discussed earlier, the U.S. applies AD duties retroactively so that foreign firms pay estimated AD duties at the beginning of the period, and then when $\mathrm{AD}$ duties are re-estimated at the end of the period, they pay additional duties or receive a refund, depending on whether the $\mathrm{AD}$ duty increased or decreased over the period. Denoting the refund duty rate for sales during period $i$ by $r_{i}$, with $r_{i}=\left(p_{i} \cdot T_{i}-p_{0}^{f}\right)$ if $p_{i} \leq p_{0}^{f}$ and $r_{i}=\left(p_{0}^{f} \cdot T_{i}-p_{0}^{f}\right)$ if $p_{i}>p_{0}^{f}$, we can analyze the effect of introducing "retro-activeness" in the administrative review process by analyzing the following problem:
} 
The dynamic pricing problem of the foreign firm would involve choosing the sequence of its foreign prices, as well as the sequence of its domestic prices. To characterize the optimal sequence for the domestic prices, however, we can focus on the problem of maximizing the discounted profit from the domestic market by choosing the optimal domestic price sequence for a given $\mathrm{p}_{0}^{\mathrm{f}}$ (optimally chosen in the initial period). This is because only the initial foreign price will matter in determining all subsequent $\mathrm{AD}$ duties for the domestic market.

Therefore, we analyze the following optimization problem, taking $p_{0}^{\mathrm{f}}$ and $\mathrm{p}_{-1} \in[0, \infty)$ as given:

$$
\operatorname{Sup}_{\left\{p_{i}\right\}_{i=0}^{\infty}} \sum_{i=0}^{\infty} \delta^{i}\left(p_{i}-c\right) \cdot q\left(p_{i} \cdot T_{i}\left(p_{i-1}\right)\right) \text { with } p_{i} \in[0, \infty), i=0,1,2, \ldots
$$

or, the corresponding dynamic programming problem:

$$
\mathrm{V}\left(\mathrm{p}_{-1}\right)=\operatorname{Sup}_{\mathrm{p} \in[0, \infty)}\left[(\mathrm{p}-\mathrm{c}) \cdot \mathrm{q}\left(\mathrm{p} \cdot \mathrm{T}\left(\mathrm{p}_{-1}\right)\right)+\delta \mathrm{V}(\mathrm{p})\right]
$$

under proper conditions that guarantee the equivalence between the above two problems.

Denote the supremum function resulting from (2) by $\mathrm{V}^{*}\left(\mathrm{p}_{-1}\right)$ and the value function satisfying (3) by $\mathrm{V}\left(\mathrm{p}_{-1}\right)$. Given the existence, uniqueness, and equivalence of $\mathrm{V}^{*}\left(\mathrm{p}_{-1}\right)$ and $\mathrm{V}\left(\mathrm{p}_{-1}\right)$, we can describe the optimal pricing path of the foreign firm facing the AD policy by analyzing the optimal policy correspondence $\mathrm{G}:[0, \infty) \rightarrow[0, \infty)$, defined by

$$
\mathrm{G}\left(\mathrm{p}_{-1}\right)=\left\{\mathrm{p} \in[0, \infty): \mathrm{V}\left(\mathrm{p}_{-1}\right)=(\mathrm{p}-\mathrm{c}) \cdot \mathrm{q}\left(\mathrm{p} \cdot \mathrm{T}\left(\mathrm{p}_{-1}\right)\right)+\delta \mathrm{V}(\mathrm{p})\right\}
$$

Lemma 1 specifies the conditions that enable such analysis.

$$
\operatorname{Sup}_{\left\{p_{i}\right\}_{i=0}^{\infty}} \sum_{i=0}^{\infty} \delta^{i}\left[\left(p_{i}-c\right)+r_{i}\right] \cdot q\left(p_{i} \cdot T_{i}\left(p_{i-1}\right)\right) .
$$

However, it can be shown that a model with this retroactive feature will generate qualitatively identical results with respect to the dynamic pricing behavior as the model without retro-activeness. From now on, thus, we will restrict our attention to the simpler model in (1). This basic model is also consistent with the structure of the EU's antidumping law, which lacks retro-activeness in its administrative review process. 
Lemma 1. If $q\left(p^{c}\right) \geq 0$ is a bounded, continuous, and strictly decreasing (when $\left.q\left(p^{c}\right)>0\right)$ function in $p^{c} \equiv \mathbf{p} \cdot \mathbf{T} \in[0, \infty)$, and there exists a constant $\bar{p}>0$ s.t $q\left(p^{c}\right)=0$ for all $p^{c} \geq \bar{p}$, then there exist unique solutions for (2) and (3), with $V *\left(p_{-1}\right)$ and $V\left(p_{-1}\right)$ being bounded, continuous, and identical functions to each other. $G\left(p_{-1}\right)$ is non-empty, compact-valued and upper-hemi continuous correspondence. (See appendix for proof)

Lemma 1 implies that we can use the dynamic programming problem (3) for almost any reasonable demand functions to analyze the problem (2). For further characterization of $G(p)$ and $V(p)$, however, we need to introduce further constraints on $q\left(p^{c}\right)$ :

(A1) $\underset{\mathrm{p}}{\operatorname{Arg} \max }[(\mathrm{p}-\mathrm{c}) \mathrm{q}(\mathrm{p})]<\mathrm{p}_{0}^{\mathrm{f}}$ : the foreign firm has an incentive to dump $\left(\mathrm{p}<\mathrm{p}_{0}^{\mathrm{f}}\right)$ in the absence of AD policy.

(A2) $\mathrm{q}\left(\mathrm{p}^{\mathrm{c}}\right)$ is twice differentiable.

(A3) $\quad q\left(p_{0}^{\mathrm{f}} \cdot\left(\mathrm{p}_{0}^{\mathrm{f}} / \mathrm{c}\right)\right)>0$.

(A4) $\mathrm{q}\left(\mathrm{p}^{\mathrm{c}}\right)$ is not too convex so that $\partial^{2} \pi(\mathrm{p} ; \mathrm{T}) / \partial \mathrm{p} \partial \mathrm{T}=\left(\partial \mathrm{q}\left(\mathrm{p}^{\mathrm{c}}\right) / \partial \mathrm{p}^{\mathrm{c}}\right) \cdot \mathrm{p}+(\mathrm{p}-\mathrm{c}) \cdot\left[\left(\partial \mathrm{q}\left(\mathrm{p}^{\mathrm{c}}\right) / \partial \mathrm{p}^{\mathrm{c}}\right)+\right.$ $\left.\left(\partial^{2} q\left(p^{c}\right) / \partial p^{c 2}\right) \cdot p^{c}\right]<0$ for $p>c, T \leq p_{0}^{f} / c$, and $q\left(p^{c}\right)>0$, where $\pi(p ; T)=(p-c) \cdot q(p \cdot T)$.

(A1) simply requires the demand conditions to be relevant for our analysis of the foreign firm's dynamic pricing under $\mathrm{AD}$ policy. (A2) facilitates the analysis by enabling us to use differentiation. (A3) is a sufficient condition for positive sales along the optimal pricing path, which largely simplifies the analysis without affecting the results. ${ }^{9,10}$ Finally, (A4) implies that the cost of setting a price higher than the static optimal price $\left(\mathrm{p}^{*}\right.$ satisfying $\left.\partial \pi\left(\mathrm{p}=\mathrm{p}^{*} ; \mathrm{T}\right) / \partial \mathrm{p}=0\right)$ is increasing as the $\mathrm{AD}$ duty increases and it plays a crucial role in the following characterization of the optimal pricing path. ${ }^{11}$

\footnotetext{
${ }^{9}$ As discussed in Gallaway et al. (1999), most of U.S. AD duties have turned out to be non-prohibitive, providing a justification for this simplifying assumption.

${ }_{10}$ If a foreign firm chooses not to export its product to the U.S. market under a AD duty, then the AD duty will remain at the same level. This generates a pricing path where a current period state variable (the current dumping duty) may depend on the price choices made more than one period before, necessitating the use of a recursive method of non-conventional form to analyze the dynamic optimization problem. We can show that all the major results of the following analysis continue to be true under the possibility of a prohibitive AD duty, thus (A3) merely simplifies the analysis.

${ }^{11} \mathrm{q}\left(\mathrm{p}^{\mathrm{c}}\right)$ being a concave function $\left(\partial^{2} \mathrm{q}\left(\mathrm{p}^{\mathrm{c}}\right) / \partial \mathrm{p}^{\mathrm{c} 2} \leq 0\right)$ is a sufficient condition for (A4). (A4) is also a sufficient condition for the second order condition for maximizing $\pi(\mathrm{p} ; \mathrm{T})$ with respective to $\mathrm{p}: \partial^{2} \pi(\mathrm{p} ; \mathrm{T}) / \partial \mathrm{p}^{2}=\mathrm{T} \cdot\left[2 \cdot\left(\partial \mathrm{q}\left(\mathrm{p}^{\mathrm{c}}\right) / \partial \mathrm{p}^{\mathrm{c}}\right)\right.$ $\left.+(\mathrm{p}-\mathrm{c}) \cdot \mathrm{T} \cdot\left(\partial^{2} \mathrm{q}\left(\mathrm{p}^{\mathrm{c}}\right) / \partial \mathrm{p}^{\mathrm{c} 2}\right)\right]<0$. An alternative condition with $\partial^{2} \pi(\mathrm{p} ; \mathrm{T}) / \partial \mathrm{p} \partial \mathrm{T}>0$, will imply a distinctively different and interesting pricing dynamics under AD policy, as discussed in footnote 12. However, the following analysis will focus on the case with (A4), because the empirical findings on the price dynamics largely support the hypotheses generated by the model with (A4) rather than the ones generated from assuming $\partial^{2} \pi(\mathrm{p} ; \mathrm{T}) / \partial \mathrm{p} \partial \mathrm{T}>0$.
} 
With (A1)-(A4), the following lemma provides sharper descriptions of $\mathrm{V}(\mathrm{p})$, as well as narrowing down the economically relevant domain and the image of $G(p)$ on which we will focus our analysis.

Lemma 2. $V(p)$ is a strictly increasing function in $p \in\left[c, p_{0}^{f}\right)$. If the foreign firm chooses its initial price $p_{0}$ in the absence of $A D$ duties $\left(T_{0}=1\right)$, then we can focus on the optimal pricing path where $p_{i} \in\left(c, p_{0}^{f}\right]$ for $i=0,1,2, \ldots$, without loss of generality. (See appendix for proof)

It is easy to understand why $\mathrm{V}(\mathrm{p})$ is an increasing function because the AD duty will be lower with higher values for $\mathrm{p}\left(<\mathrm{p}_{0}^{\mathrm{f}}\right)$, implying more favorable environment for the dynamic profit maximization. The intuition for why the optimal pricing path is bounded between $\mathrm{c}$ and $\mathrm{p}_{0}^{\mathrm{f}}$ is also relatively straightforward. First, the firm would never want to set $\mathrm{p} \leq \mathrm{c}$ because it can raise the current period payoff to a positive value from a negative or zero one by setting $\mathrm{p}>\mathrm{c}$, and this will also raise the next period's discounted payoff by inducing a lower AD duty. Second, the firm would not want to price above $\mathrm{p}_{0}^{\mathrm{f}}$ in the initial period because, given (A1) and (A4) which guarantees the second order condition for the current period profit maximization problem hold, it will get a higher current period profit for setting $\mathrm{p}=\mathrm{p}_{0}^{\mathrm{f}}$ than for any $\mathrm{p}>\mathrm{p}_{0}^{\mathrm{f}}$. Additionally, the next period $A D$ duty will be zero for any $p \geq p_{0}^{f}$ with a constant value for $V(p)$. This superiority of setting $\mathrm{p}=\mathrm{p}_{0}^{\mathrm{f}}$ over $\mathrm{p}>\mathrm{p}_{0}^{\mathrm{f}}$ will continue to be true as long as an increase in the current $\mathrm{AD}$ duty would not make the foreign firm's static optimal price (maximizing the current period profit) to be higher than $\mathrm{p}_{0}^{\mathrm{f}}$. (A4) implies that the static optimal price will decrease as the current $A D$ duty increases, eliminating the possibility for setting $p>p_{0}^{f}$ in the optimal pricing path.

Based on Lemma 2, we will focus on the characterization of $G(p)$ on $p \in\left(c, p_{0}^{f}\right]$. Denote $\max \{G(p)\}$ by $h(p)$ and $\min \{G(p)\}$ by $l(p)$. Then, we can derive the following lemma.

Lemma 3. The optimal correspondence $G(p)$ is increasing in $p$ in the sense that $h\left(p^{\prime \prime}\right) \leq l\left(p^{\prime}\right)$ for all $\mathbf{p}^{\prime}>\mathbf{p}^{\prime \prime} \in\left(\mathbf{c}, \mathbf{p}_{0}^{\mathrm{f}}\right]$. (See appendix for proof) 
Lemma 3 implies that the foreign firm's optimal price in the current period does not increase when the current $\mathrm{AD}$ duty increases. Figure 1 is helpful in understanding this result. Figure 1a depicts profit functions $\left(\pi\left(\mathrm{p} ; \mathrm{T}^{\prime}\right), \pi\left(\mathrm{p} ; \mathrm{T}^{\prime \prime}\right)\right)$ with different $\mathrm{AD}$ duties of the current period $\left(\mathrm{T}^{\prime}<\mathrm{T}^{\prime \prime}\right)$, and Figure $1 \mathrm{~b}$ depicts the increasing value function as a function of the current period price $(\mathrm{V}(\mathrm{p}))$. By definition, setting $\mathrm{p}=1\left(\mathrm{p}_{0}^{\mathrm{f}} / \mathrm{T}^{\prime}=\mathrm{p}^{\prime}\right)$ maximizes the current discounted payoff when the current $A D$ duty is $T^{\prime} ; \pi\left(1\left(p^{\prime}\right) ; T^{\prime}\right)+\delta V\left(1\left(p^{\prime}\right)\right) \geq \pi\left(p ; T^{\prime}\right)+\delta V(p)$ for all $p \in(c$, $\mathrm{p}_{0}^{\mathrm{f}}$ ]. If the current period $\mathrm{AD}$ duty increases to $\mathrm{T}$ ", the profit function shifts down in such a way that $\partial \pi\left(\mathrm{p} ; \mathrm{T}^{\prime}\right) / \partial \mathrm{p}>\partial \pi\left(\mathrm{p} ; \mathrm{T}^{\prime \prime}\right) / \partial \mathrm{p}$ for all $\mathrm{p}$ due to (A4). This shift in profit function in response to an increase in the $\mathrm{AD}$ duty makes setting the current period price higher than $1\left(\mathrm{p}^{\prime}\right)$ even less attractive than before. Note that the foreign firm tries to balance between the current period profit loss against the future discounted profit gain in setting the current price higher than its static optimum. Because a higher current $\mathrm{AD}$ duty will raise the current period profit loss associated with higher prices, it induces the foreign firm to choose a lower current price than before, if not an equal price.

Based on Lemma 1-3, we can now characterize the dynamic pricing behavior of the foreign firm in the presence of $\mathrm{AD}$ policy as follows:

\section{Proposition 1. When $q\left(p^{c}\right)$ satisfies (A1)-(A4), there exist $\delta^{\mathfrak{c}} \in(0,1]$ such that}

i) for $\delta>\delta^{c}$, the foreign firm will set $p_{i}=p_{0}^{f}$, thus $T_{i}=1$ for $i=0,1,2, \ldots$.

ii) for $\delta<\delta^{c}$, the foreign firm will set $p_{0}<p_{0}^{f}$, thus $T_{0}>1$ with $p_{0} \geq p_{1} \geq p_{2} \ldots$, thus $T_{0} \leq T_{1} \leq T_{2} \leq \ldots$ (See appendix for proof)

As mentioned earlier, the optimal price is set to balance the current period profit loss against the discounted profit gain in the next period. Therefore, we will observe the foreign firm dumping its products only when the foreign firm values the current period profit high enough relative to its future discounted profit $\left(\delta<\delta^{c}\right)$. If the foreign firm dumps in the initial period, then rather surprisingly the foreign firm will never try to reduce its dumping margin through the administrative review process, according to Proposition 1.

This is shown in Figure 2a, which depicts possible optimal policy correspondences for firms with $\delta<\delta^{\mathrm{c}}$ and those with $\delta>\delta^{\mathrm{c}}$. Focusing on $\mathrm{G}\left(\mathrm{p} ; \delta<\delta^{\mathrm{c}}\right)$, suppose we begin with no AD 
duty, thus having $\mathrm{p}$ (the last period price) being $\mathrm{p}_{0}^{\mathrm{f}}$. Then, its current period optimal price is given by the policy correspondence, $\mathrm{G}\left(\mathrm{p}=\mathrm{p}_{0}^{\mathrm{f}} ; \delta<\delta^{\mathrm{c}}\right)$, which is represented by the vertical height at point $A$. This price is clearly less than $\mathrm{p}_{0}^{\mathrm{f}}$ because it is below the $45^{\circ}$ line. In fact, by translating it to the $45^{\circ}$ line at point $\mathrm{B}$, we can see it corresponds to $\mathrm{P}_{0}$. But then the optimal policy correspondence $\mathrm{G}\left(\mathrm{p} ; \delta<\delta^{\mathrm{c}}\right)$ gives us the optimal price in the next period, which is represented by point $C$ and translates to price of $P_{1}$. This process continues until we reach the steady state price of $\mathrm{p}^{\mathrm{S}}$. Thus, for firms that do not value future period's profits very highly, $\delta<$ $\delta^{c}$, optimal prices fall and, hence AD duties rise over time until reaching a steady state equilibrium. In contrast, the optimal policy correspondence function for firms that value the future relatively highly, $\delta>\delta^{\mathrm{c}}$, crosses the $45^{\circ}$ line at $\mathrm{p}_{0}^{\mathrm{f}}$, indicating that this price is the steady state equilibrium price.

The optimal policy correspondence may not behave smoothly as illustrated in Figure $2 \mathrm{~b}$, but we can easily verify that the foreign firm will never reduce its dumping margin through the review process. ${ }^{12}$ The intuition is that if a foreign firm dumps in the initial period, this behavior reveals that the firm cares its current period profit loss associated with pricing higher than its static optimum relatively more than the gain in the future discounted profit from avoiding a positive AD duty in the next period. Then, in the next period with a positive AD duty, (A4) assures that the "current" profit loss associate with higher pricing gets steeper than before, inducing the firm to reduce its price even further or to set the same price. ${ }^{13}$ Thus, the fact that a foreign firm dumps in the initial period despite the dynamic costs from future AD duties, reveals the firm's dynamic preference toward dumping.

Proposition 1 generates a specific empirical prediction: foreign firms will never try to reduce their $\mathrm{AD}$ duties through the administrative review process. Even a brief look at the U.S.

\footnotetext{
${ }^{12}$ For the case where $\partial^{2} \pi(\mathrm{p} ; \mathrm{T}) / \partial \mathrm{p} \partial \mathrm{T}>0$ instead of having (A4), it can be shown that $\mathrm{G}(\mathrm{p})$ is decreasing in $\mathrm{p}$ rather than increasing in $p$, using a similar argument as in Lemma 3. This can lead to the dynamic pricing sequence through the administrative review process where AD duties under the review will move up and down, but eventually decrease to a lower value than the initial AD duty. This is theoretically an interesting phenomenon, but is not something we generally observe in our data for the U.S. AD cases from 1980 through 1995.

${ }^{13}$ Because (A4) is a crucial assumption for this result, it may be worthwhile to identify the conditions under which (A4) is satisfied, other than the curvatures of demand curves already mentioned in Footnote 9. More specifically, one may try to relate (A4) with the price elasticity of demand, $\varepsilon_{p}(p)=-(\partial q(p) / \partial p) \cdot(p / q(p))$. Using $\partial \varepsilon_{p}(p) / \partial p$ has the sign same as that of $-\left[(\partial \mathrm{q}(\mathrm{p}) / \partial \mathrm{p})\left(1+\varepsilon_{\mathrm{p}}\right)+\mathrm{p} \cdot\left(\partial^{2} \mathrm{q}(\mathrm{p}) / \partial \mathrm{p}^{2}\right)\right]$, it is easy to show that (A4) will be satisfied as long as $\partial \varepsilon_{\mathrm{p}}(\mathrm{p}) / \partial \mathrm{p}>0$ and $\varepsilon_{\mathrm{p}}(>1)$ is close enough to 1 . This result is not too surprising because $\partial \varepsilon_{\mathrm{p}}(\mathrm{p}) / \partial \mathrm{p}>0$ can be linked to
} 
AD administrative review data can tell us that this prediction is largely wrong; approximately $45 \%$ of the initial dumping duties have been reduced through the review process during 19801995 period. Thus, we next introduce uncertainty in the enforcement of AD policy into the model, which may induce the foreign firms to reduce their dumping duties through the review.

\subsection{Model with Uncertain Enforcement of AD Policy}

As mentioned earlier, many U.S. AD cases are not ruled affirmative and, hence, do not lead to AD duties. This is despite the fact that the USDOC finds dumping in over $95 \%$ of the investigations! About half the cases are ruled negative, almost exclusively because they do not meet the injury criteria of the USITC, and a significant amount lead to terminations, suspensions or withdrawn cases based on agreements between domestic and foreign firms, often VERs (e.g., see Prusa, 1992 and Anderson, 1992;1993). In addition, the AD investigation starts only after the domestic firms or the USDOC file an AD petition against potential dumping activities. Thus, it is obvious that there exist uncertainties in the outcomes and enforcement of AD policy, especially in the initial $\mathrm{AD}$ investigation. From the foreign firm's point of view, this implies that setting $\mathrm{p}_{0}$ $<\mathrm{p}_{0}^{\mathrm{f}}$, does not necessarily incur $\mathrm{T}_{1}=\mathrm{p}_{0}^{\mathrm{f}} / \mathrm{p}_{0}>1$.

To model the dynamic pricing problem in the presence of uncertain enforcement, we classify different contingencies of $\mathrm{AD}$ enforcement into the following three categories: cases with final affirmative dumping determinations $(A D D)$, cases being ended with negative injury or dumping determinations ( $N E G)$ including the case of no AD petition filing, and cases being terminated, suspended, or withdrawn in lieu of some settlement, such as a VER (TER). Note that from a foreign exporting firm's point of view, NEG cases will require no adjustment in its pricing behavior, but TER cases will require some adjustments which can either be favorable or unfavorable ones depending on the nature of settlements it can reach.

In the presence of uncertainties in the enforcement of $\mathrm{AD}$ policy, a foreign firm's expectation on probabilities of different contingencies will play an important role in its initial pricing (dumping) decision and the following pricing decisions once it is subject to an AD duty. Given that a foreign firm dumps $\left(\mathrm{p}_{\mathrm{i}}<\mathrm{p}_{0}^{\mathrm{f}}\right)$ in the absence of any current AD duty $\left(\mathrm{T}_{\mathrm{i}}=1\right)$ at period i, let $\operatorname{Pr}(\mathrm{ADD}), \operatorname{Pr}(\mathrm{NEG})$, and $\operatorname{Pr}(\mathrm{TER}) \in[0,1]$ denote the ex ante probabilities of getting an ADD, NEG, or TER case in the next (i+1) period, respectively. By definition, $\operatorname{Pr}(\mathrm{ADD})+$

an increasing cost (consumers being more sensitive) for setting higher price as the price gets higher. However, 
$\operatorname{Pr}(\mathrm{NEG})+\operatorname{Pr}(\mathrm{TER})=1$. Note that these are ex ante probabilities, so that, for example, a firm having a very low value for $\operatorname{Pr}(\mathrm{ADD})$ may find itself to be subject to an AD duty in the next period, despite its low expectation of such a duty. As discussed later, this kind of potential "shock" to expectations will generate an interesting pattern in dynamic pricing behaviors of firms subject to $\mathrm{AD}$ duties, which will be the basis of the empirical analysis.

For analytical simplicity, we introduce the following assumptions on the nature of uncertainties surrounding the $\mathrm{AD}$ investigation. First, once an AD duty is imposed, the initial $\mathrm{AD}$ duty and the following administrative reviews will be perfectly enforced, applying $\mathrm{T}_{\mathrm{i}+1}=$ $\mathrm{p}_{0}^{\mathrm{f}} / \mathrm{p}_{\mathrm{i}}$. This fits with the observation that no injury determination by the USITC occurs during administrative reviews, which is the main source of uncertainty in the initial AD investigation. Second, once a TER case arises due to an agreement among interested parties, we assume such an agreement will be perfectly enforced, eliminating possibilities for any future AD investigation. Finally, we assume that these ex ante probabilities, $\operatorname{Pr}(\cdot)$ s are not functions of the price chosen in the absence an $\mathrm{AD}$ duty or an agreement, even though $\operatorname{Pr}(\cdot) \mathrm{s}$ may differ across different foreign firms belong to different industries. ${ }^{14}$

Given the uncertain enforcement of AD policy described above, the discounted expected payoff in the initial period, $\mathrm{EV}\left(\mathrm{p}_{0}^{\mathrm{f}}\right)$ will be given by:

$$
\begin{aligned}
& \operatorname{EV}\left(\mathrm{p}_{0}^{\mathrm{f}}\right)=\left\{\begin{array}{l}
\left(\mathrm{p}_{0}^{\mathrm{e}}-\mathrm{c}\right) \cdot \mathrm{q}\left(\mathrm{p}_{0}^{\mathrm{e}}\right)+\operatorname{Pr}(\mathrm{TER}) \times\left[\delta \cdot\left(\mathrm{p}_{0}^{\mathrm{t} 0}-\mathrm{c}\right) \cdot \mathrm{q}\left(\mathrm{p}_{0}^{\mathrm{t} 0}\right)+\delta^{2} \cdot\left(\mathrm{p}_{1}^{\mathrm{t} 0}-\mathrm{c}\right) \cdot \mathrm{q}\left(\mathrm{p}_{1}^{\mathrm{t} 0}\right)+\cdots\right] \\
+\operatorname{Pr}(\mathrm{ADD}) \times\left[\delta \cdot\left(\mathrm{p}_{0}^{\mathrm{d} 0}-\mathrm{c}\right) \cdot \mathrm{q}\left(\mathrm{p}_{0}^{\mathrm{d} 0} \cdot\left(\mathrm{p}_{0}^{\mathrm{f}} / \mathrm{p}_{0}^{\mathrm{e}}\right)\right)+\delta^{2} \cdot\left(\mathrm{p}_{1}^{\mathrm{d} 0}-\mathrm{c}\right) \cdot \mathrm{q}\left(\mathrm{p}_{1}^{\mathrm{d} 0} \cdot\left(\mathrm{p}_{0}^{\mathrm{f}} / \mathrm{p}_{0}^{\mathrm{d} 0}\right)\right)+\cdots\right]
\end{array}\right\} \\
& +\operatorname{Pr}(\mathrm{NEG}) \times\left\{\begin{array}{l}
\delta \cdot\left(\mathrm{p}_{1}^{\mathrm{e}}-\mathrm{c}\right) \cdot \mathrm{q}\left(\mathrm{p}_{1}^{\mathrm{e}}\right)+\operatorname{Pr}(\mathrm{TER}) \times\left[\delta^{2}\left(\mathrm{p}_{0}^{\mathrm{t} 1}-\mathrm{c}\right) \cdot \mathrm{q}\left(\mathrm{p}_{0}^{\mathrm{t} 1}\right)+\delta^{3} \cdot\left(\mathrm{p}_{1}^{\mathrm{t} 1}-\mathrm{c}\right) \cdot \mathrm{q}\left(\mathrm{p}_{1}^{\mathrm{tl}}\right)+\cdots\right] \\
+\operatorname{Pr}(\mathrm{ADD}) \times\left[\delta^{2} \cdot\left(\mathrm{p}_{0}^{\mathrm{d} 1}-\mathrm{c}\right) \cdot \mathrm{q}\left(\mathrm{p}_{0}^{\mathrm{d} 1} \cdot\left(\mathrm{p}_{0}^{\mathrm{f}} / \mathrm{p}_{1}^{\mathrm{e}}\right)\right)+\delta^{3} \cdot\left(\mathrm{p}_{1}^{\mathrm{d} 1}-\mathrm{c}\right) \cdot \mathrm{q}\left(\mathrm{p}_{1}^{\mathrm{d} 1}\left(\mathrm{p}_{0}^{\mathrm{f}} / \mathrm{p}_{0}^{\mathrm{d} 1}\right)\right)+\cdots\right.
\end{array}\right\} \\
& +\operatorname{Pr}(\mathrm{NEG})^{2} \times\left\{\begin{array}{l}
\delta^{2} \cdot\left(\mathrm{p}_{2}^{\mathrm{e}}-\mathrm{c}\right) \cdot \mathrm{q}\left(\mathrm{p}_{2}^{\mathrm{e}}\right)+\operatorname{Pr}(\mathrm{TER}) \times\left[\delta^{3} \cdot\left(\mathrm{p}_{0}^{\mathrm{t} 2}-\mathrm{c}\right) \cdot \mathrm{q}\left(\mathrm{p}_{0}^{\mathrm{t} 2}\right)+\delta^{4} \cdot\left(\mathrm{p}_{1}^{\mathrm{t} 2}-\mathrm{c}\right) \cdot \mathrm{q}\left(\mathrm{p}_{1}^{\mathrm{t} 2}\right)+\cdots\right] \\
+\operatorname{Pr}(\mathrm{ADD}) \times\left[\delta^{3} \cdot\left(\mathrm{p}_{0}^{\mathrm{d} 2}-\mathrm{c}\right) \cdot \mathrm{q}\left(\mathrm{p}_{0}^{\mathrm{d} 2} \cdot\left(\mathrm{p}_{0}^{\mathrm{f}} / \mathrm{p}_{2}^{\mathrm{e}}\right)\right)+\delta^{4} \cdot\left(\mathrm{p}_{1}^{\mathrm{d} 2}-\mathrm{c}\right) \cdot \mathrm{q}\left(\mathrm{p}_{1}^{\mathrm{d} 2} \cdot\left(\mathrm{p}_{0}^{\mathrm{f}} / \mathrm{p}_{0}^{\mathrm{d} 2}\right)\right)+\cdots\right]
\end{array}\right\} \\
& +\cdots,
\end{aligned}
$$

increasing price elasticity w.r.t. $\mathrm{p}$, is neither a sufficient nor a necessary condition for (A4).

${ }^{14}$ It is conceivable that pricing (dumping) behavior affects the USITC injury determination, which largely determines outcomes. However, given we assume that each individual firm is a small player in a monopolistically competitive industry (the implicit assumption behind the modeling in this paper), $\operatorname{Pr}(\mathrm{ADD})$ and $\operatorname{Pr}(\mathrm{TER})$ can be considered as exogenous variables from an individual firm's point of view and mainly depend on the industry characteristics. 
where $p_{i}^{e}$ represents the price to be set in period $i$ when neither an ADD case nor a TER case has ever occurred until period $\mathrm{i},\left\{\mathrm{p}_{0}^{\mathrm{di}}, \mathrm{p}_{1}^{\mathrm{di}}, \mathrm{p}_{2}^{\mathrm{di}}, \ldots\right\}$ denotes the price sequence from period $\mathrm{i}+1$ in which an initial AD duty is imposed based on $\mathrm{p}_{\mathrm{i}}^{\mathrm{e}}$, and $\left\{\mathrm{p}_{0}^{\mathrm{ti}}, \mathrm{p}_{1}^{\mathrm{ti}}, \mathrm{p}_{2}^{\mathrm{ti}}, \ldots\right\}$ denotes the price sequence from period $i+1$ in which a TER occurs with a specific value for $p_{i}^{e}$. Because the AD duty is determined by applying $T_{i+1}=p_{0}^{f} / p_{i}$, no previous periods' pricing but only $\mathrm{p}_{\mathrm{i}}^{\mathrm{e}}$ will matter in determining $\left\{\mathrm{p}_{0}^{\mathrm{di}}, \mathrm{p}_{1}^{\mathrm{di}}, \mathrm{p}_{2}^{\mathrm{di}}, \ldots\right\}$. Given that a TER outcome occurs in the presence of a possible ADD case, once again only $\mathrm{p}_{\mathrm{i}}^{\mathrm{e}}$ (among all pervious periods' pricing) will play a role in determining $\left\{\mathrm{p}_{0}^{\mathrm{ti}}, \mathrm{p}_{1}^{\mathrm{ti}}, \mathrm{p}_{2}^{\mathrm{ti}}, \ldots\right\} .{ }^{15}$

If neither an ADD nor a TER outcome has ever occurred, then the foreign firm will face the same problem as its initial problem regarding its choice of $p_{i}^{e}$ for $i=1,2,3, \ldots$. Thus, the optimal price will be identical to the initial optimal price as long as the foreign firm has continued to have negative cases. Denote this "initial" optimal choice to be $\mathrm{p}_{0}^{\mathrm{E}}$. If a AD duty $\left(\mathrm{T}_{0}^{\mathrm{D}}=\mathrm{p}_{0}^{\mathrm{f}} / \mathrm{p}_{0}^{\mathrm{E}}\right)$ is ever-imposed for the first time, then the foreign firm faces the same certainty problem described in Section 3.1 from that period on. Thus, we can use the same value function as in Section 3.1 to represent the discounted profit from that period on, $V\left(p_{0}^{E}\right)$ : the solution to the problem in (3). If a TER case occurs in period $i+1$, then $\mathrm{p}_{0}^{\mathrm{E}}$ will determine the following periods' pricing path, $\left\{\mathrm{p}_{0}^{\mathrm{ti}}, \mathrm{p}_{1}^{\mathrm{ti}}, \mathrm{p}_{2}^{\mathrm{ti}}, \ldots\right\}$, yielding the discounted profit from that period on, $\left(\mathrm{p}_{0}^{\mathrm{ti}}-\mathrm{c}\right) \cdot \mathrm{q}\left(\mathrm{p}_{0}^{\mathrm{ti}}\right)+\delta\left(\mathrm{p}_{1}^{\mathrm{ti}}-\mathrm{c}\right) \mathrm{q}\left(\mathrm{p}_{1}^{\mathrm{ti}}\right)+\delta^{2}\left(\mathrm{p}_{2}^{\mathrm{ti}}-\mathrm{c}\right) \mathrm{q}\left(\mathrm{p}_{2}^{\mathrm{ti}}\right)+\cdots$. Denote this discounted profit for a TER case by $\mathrm{V}^{\mathrm{T}}\left(\mathrm{p}_{0}^{\mathrm{E}}\right)$, using the fact that $\mathrm{p}_{0}^{\mathrm{E}}$ is a major variable that determines the pricing path for a TER case. Then, we can rewrite the discounted expected payoff in the initial period as:

\footnotetext{
${ }^{15}$ In determining the outcome of an agreement for a TER case, it is obvious that the level of $\mathrm{p}_{\mathrm{i}}^{\mathrm{e}}$ relative to $\mathrm{p}_{0}^{\mathrm{f}}$ will play a crucial role, because a VER often assigns export licenses based on the pervious period market share of relevant firms and the possible bargaining for an agreement will take place with an $\mathrm{AD}$ duty being considered as a possible alternative to an agreement.
} 


$$
\begin{aligned}
\mathrm{EV} & \left(\mathrm{p}_{0}^{\mathrm{f}}\right)=\left(\mathrm{p}_{0}^{\mathrm{E}}-\mathrm{c}\right) \mathrm{q}\left(\mathrm{p}_{0}^{\mathrm{E}}\right) \times\left[1+\delta \cdot \operatorname{Pr}(\mathrm{NEG})+\delta^{2} \cdot \operatorname{Pr}(\mathrm{NEG})^{2}+\delta^{3} \cdot \operatorname{Pr}(\mathrm{NEG})^{3}+\cdots\right] \\
& +\delta \cdot \operatorname{Pr}(\mathrm{ADD}) \cdot \mathrm{V}\left(\mathrm{p}_{0}^{\mathrm{E}}\right) \times\left[1+\delta \cdot \operatorname{Pr}(\mathrm{NEG})+\delta^{2} \cdot \operatorname{Pr}(\mathrm{NEG})^{2}+\delta^{3} \cdot \operatorname{Pr}(\mathrm{NEG})^{3}+\cdots\right] \\
& +\delta \cdot \operatorname{Pr}(\mathrm{TER}) \cdot \mathrm{V}^{\mathrm{T}}\left(\mathrm{p}_{0}^{\mathrm{E}}\right) \times\left[1+\delta \cdot \operatorname{Pr}(\mathrm{NEG})+\delta^{2} \cdot \operatorname{Pr}(\mathrm{NEG})^{2}+\delta^{3} \cdot \operatorname{Pr}(\mathrm{NEG})^{3}+\cdots\right] \\
= & \left\{\left(\mathrm{p}_{0}^{\mathrm{E}}-\mathrm{c}\right) \cdot \mathrm{q}\left(\mathrm{p}_{0}^{\mathrm{E}}\right)+\delta \cdot\left[\operatorname{Pr}(\mathrm{ADD}) \cdot \mathrm{V}\left(\mathrm{p}_{0}^{\mathrm{E}}\right)+\operatorname{Pr}(\mathrm{TER}) \cdot \mathrm{V}^{\mathrm{T}}\left(\mathrm{p}_{0}^{\mathrm{E}}\right)\right]\right\}[1-\delta \cdot \operatorname{Pr}(\mathrm{NEG})]
\end{aligned}
$$

Because the ex ante probabilities, $\operatorname{Pr}(\cdot) \mathrm{s}$ are not functions of $\mathrm{p}_{0}^{\mathrm{E}}$, the dynamic pricing problem under uncertain enforcement is reduced to find out $\mathrm{p}_{0}^{\mathrm{E}}$ satisfying:

$$
\operatorname{Sup}_{\mathrm{p}_{0}^{\mathrm{E}} \in\left(\mathrm{c}, \mathrm{p}_{0}^{\mathrm{f}}\right]}\left\{\left(\mathrm{p}_{0}^{\mathrm{E}}-\mathrm{c}\right) \cdot \mathrm{q}\left(\mathrm{p}_{0}^{\mathrm{E}}\right)+\delta \cdot\left[\operatorname{Pr}(\mathrm{ADD}) \cdot \mathrm{V}\left(\mathrm{p}_{0}^{\mathrm{E}}\right)+\operatorname{Pr}(\mathrm{TER}) \cdot \mathrm{V}^{\mathrm{T}}\left(\mathrm{p}_{0}^{\mathrm{E}}\right)\right]\right\}
$$

and then the optimal pricing path under the administrative review process will follow $G\left(p_{0}^{E}\right)$ defined in (4) of Section 3.1. ${ }^{16}$ Therefore, to analyze the effect of introducing uncertain enforcement on the foreign firm's dynamic pricing path under the administrative review process, we should first focus on how changes in $\operatorname{Pr}(\mathrm{ADD})$ and $\operatorname{Pr}(\mathrm{TER})$ affect $\mathrm{p}_{0}^{\mathrm{E}}$. Proposition 2 provides results on this issue.

\section{Proposition 2.}

i) $\mathbf{p}_{0}^{\mathrm{E}}$ is increasing in $\operatorname{Pr}(\mathrm{ADD})$,

ii) $p_{0}^{E}$ is decreasing in $\operatorname{Pr}(T E R)$ if $V^{T}(p)$ is strictly decreasing in $p \in\left(c, p_{0}^{f}\right]$, and

$p_{0}^{E}$ is increasing in $\operatorname{Pr}(T E R)$ if $V^{T}(p)$ is strictly increasing in $p \in\left(c, p_{0}^{\mathrm{f}}\right]$. (See appendix for proof)

It is easy to understand why an increase in $\operatorname{Pr}(\mathrm{ADD})$ will induce the foreign firm to choose a higher (at least not lower) value for its initial price $\left(\mathrm{p}_{0}^{\mathrm{E}}\right){ }^{17}$ Due to the same reason as

\footnotetext{
${ }^{16}$ In the presence of a large value for $\operatorname{Pr}(\mathrm{TER})$ together with $\mathrm{V}^{\mathrm{T}}(\mathrm{p})$ being strictly decreasing in $\mathrm{p}$, we cannot eliminate the possibility of having $p_{0}^{E}<c$. Because we have characterized $G(p)$ and $V(p)$ on $p \in\left(c, p_{0}^{f}\right]$, we will focus on the case where $\mathrm{p}_{0}^{\mathrm{E}}>\mathrm{c}$.

${ }^{17}$ If $\mathrm{V}(\mathrm{p})$ is differentiable at $\mathrm{p}_{0}^{\mathrm{E}}=\mathrm{p}_{0}^{\mathrm{E}^{*}}$, and $\mathrm{p}_{0}^{\mathrm{E}^{*}}$ is an interior solution that satisfies the first and the second order conditions for (6), then $\mathrm{p}_{0}^{\mathrm{E}}$ is strictly increasing in $\operatorname{Pr}(\mathrm{ADD})$ at $\mathrm{p}_{0}^{\mathrm{E}}=\mathrm{p}_{0}^{\mathrm{E}^{*}}$ in the sense that $\partial \mathrm{p}_{0}^{\mathrm{E}} / \partial \operatorname{Pr}(\mathrm{ADD})>0$. This can be easily shown by applying the envelope theorem to the f.o.c. for (6). However, $V(p)$ is only shown to be
} 
under certain enforcement, the optimal price (in the absence of the AD duty) $\mathrm{p}_{0}^{\mathrm{E}}$ is set to balance the current period profit loss from setting the price higher than its static optimum against the future expected discounted profit gain from reducing the AD duty that the firm would incur once it becomes subject to a $\mathrm{AD}$ duty. A higher value for $\operatorname{Pr}(\mathrm{ADD})$ raises the cost for choosing a lower value for $\mathrm{p}_{0}^{\mathrm{E}}$, because it implies a higher probability of getting a costly (note that $\mathrm{V}(\mathrm{p})$ is strictly increasing in $\mathrm{p}$ ) $\mathrm{AD}$ duty, reducing the incentive to set $\mathrm{p}_{0}^{\mathrm{E}}$ to be closer to its static optimum price, $\mathrm{p}^{*}$.

The effect of an increased value for $\operatorname{Pr}(T E R)$ on $\mathrm{p}_{0}^{\mathrm{E}}$ depends on whether $\mathrm{V}^{\mathrm{T}}(\mathrm{p})$ is strictly decreasing or increasing in $\mathrm{p}$. If $\mathrm{V}^{\mathrm{T}}(\mathrm{p})$ is strictly increasing in $\mathrm{p}$, a higher value for $\operatorname{Pr}(\mathrm{TER})$ inflicts a higher cost for choosing a lower value for $\mathrm{p}_{0}^{\mathrm{E}}$ because a lower value for $\mathrm{p}_{0}^{\mathrm{E}}$ will work as a disadvantage under a TER case. If a lower value for $\mathrm{p}_{0}^{\mathrm{E}}$ works as an advantage under a TER case $\left(\mathrm{V}^{\mathrm{T}}(\mathrm{p})\right.$ is strictly decreasing in $\left.\mathrm{p}\right)$, then a higher value for $\operatorname{Pr}(\mathrm{TER})$ will provide an extra incentive to choose a lower value for $\mathrm{p}_{0}^{\mathrm{E}}$. When an agreement under a TER case takes a form of VER where more export licenses are given to a firm with higher market share, like the one considered in Anderson (1992:1993), then a lower $\mathrm{p}_{0}^{\mathrm{E}}$ will work as an advantage under such an agreement. $^{18}$ If a TER agreement is reached through a bargaining process between foreign and domestic firms with the ADD case as a threat point, however, it is possible to have a case where a lower $\mathrm{p}_{0}^{\mathrm{E}}$ works as a disadvantage for the foreign firm under a TER case. Therefore, which type of an agreement prevails under a TER case is an empirical question and will be analyzed in the following empirical section.

differentiable almost everywhere, implying that there may exist a set (with measure zero) where $V(p)$ fails to be differentiable. Even in that case, $\mathrm{p}_{0}^{\mathrm{E}}$ is non-decreasing in $\operatorname{Pr}(\mathrm{ADD})$.

${ }^{18}$ In this case, the maximization in (6) can be used to demonstrate a result (Proposition 1) of James E. Anderson (1993) that an increased enforcement $(\beta)$ may intensify dumping behaviors for a sufficiently large probability of an $\operatorname{AD} \operatorname{VER}(\gamma)$. Using that $\operatorname{Pr}(\mathrm{ADD})=\beta \cdot(1-\gamma)$ and $\operatorname{Pr}(\mathrm{TER})=\beta \cdot \gamma,(6)$ can be rewritten as

(6') $\left.\operatorname{Sup}_{\mathrm{p}_{0}^{\mathrm{E}} \in\left(\mathrm{c}, \mathrm{p}_{0}^{\mathrm{f}}\right]}\left\{\left(\mathrm{p}_{0}^{\mathrm{E}}-\mathrm{c}\right) \cdot \mathrm{q}\left(\mathrm{p}_{0}^{\mathrm{E}}\right)+\delta \cdot \mid \beta \cdot(1-\gamma) \cdot \mathrm{V}\left(\mathrm{p}_{0}^{\mathrm{E}}\right)+\beta \cdot \gamma \cdot \mathrm{V}^{\mathrm{T}}\left(\mathrm{p}_{0}^{\mathrm{E}}\right)\right]\right\}$.

When $\gamma$ is close to 1 , then an increase in $\beta$ will raise $\operatorname{Pr}($ TER) without really affecting $\operatorname{Pr}($ ADD), thus strengthening the incentive to dump (setting a lower $\left.p_{0}^{E}\right)$ as $V^{T}\left(p_{0}^{E}\right)$ is strictly decreasing in $p_{0}^{E}$. 
Given the analysis of effects of $\operatorname{Pr}(\mathrm{ADD})$ and $\operatorname{Pr}(\mathrm{TER})$ on $\mathrm{p}_{0}^{\mathrm{E}}$, we can now discuss the effect of uncertainties in the enforcement of $\mathrm{AD}$ policy on the dynamic pricing (AD duty) path under an administrative review process. In contrast to the certain enforcement case where the $\mathrm{AD}$ duty can only increase (or stay the same) through the review process, the presence of uncertainty in enforcement generates the possibility for diminishing $\mathrm{AD}$ duties through the review process. The following Corollary 1 demonstrates this. ${ }^{19}$

Corollary 1. Assume that there exists a unique stationary equilibrium under certain enforcement, denoted by $\mathbf{p}^{\mathrm{s}}$. $^{20}$

i) If $p^{S}=p_{0}^{f}$, there exists a $\operatorname{Pr}^{c}(A D D) \in(0,1]$ such that the foreign firm sets $p_{0}^{E}<p_{0}^{f}$ for $\operatorname{Pr}(A D D)<\operatorname{Pr}^{c}(A D D)$. If an AD duty is imposed, with $p_{0}^{E}<p_{0}^{f}$ leading to AD duty $T_{0}^{d}=p_{0}^{f} / p_{0}^{E}$, then the foreign firm will choose it's pricing path so that the AD duty decreases toward zero through the review process.

ii) If $\operatorname{Arg} \max [(p-c) q(p)]<p^{s}<p_{0}^{f}$, there exists a $\operatorname{Pr}^{c}(A D D) \in(0,1]$ such that the foreign firm sets $p_{0}^{E}<p^{S}$ for $\operatorname{Pr}(A D D)<\operatorname{Pr}^{c}(A D D)$. If an AD duty is imposed, with $p_{0}^{E}<p^{S}$ leading to $A D$ duty $T_{0}^{d}=p_{0}^{f} / p_{0}^{E}$, then the foreign firm will choose it's pricing path so that the AD duty decreases toward $T^{S}=p_{0}^{f} / p^{S}$ through the review process.

(See appendix for proof)

To help explain the above results, we present Figures $3 \mathrm{a}$ and $3 \mathrm{~b}$, which contain the policy correspondences, $\mathrm{G}(\mathrm{p})$, derived from computationally solving the dynamic programming (pricing) problem based on a linear demand. Figure 3a illustrates the case where the discount factor is high enough so that the foreign firm would set $p_{0}=p_{0}^{f}=p^{s}=8$ under certain enforcement. Because $\mathrm{p}_{0}^{\mathrm{E}}$ decreases as $\operatorname{Pr}(\mathrm{ADD})$ decreases, $\mathrm{p}_{0}^{\mathrm{E}}$ will become smaller than $\mathrm{p}^{\mathrm{S}}=8$ for a low enough value of $\operatorname{Pr}(\mathrm{ADD})$ as illustrated in Figure 3a. Once a firm finds itself subject to a $\mathrm{AD}$ duty at period $\mathrm{i}$, then it will adjust its pricing through the review as indicated by

\footnotetext{
${ }^{19} \operatorname{Pr}(\mathrm{ADD})=1$ for any $\mathrm{p}_{0}^{\mathrm{E}}<\mathrm{p}_{0}^{\mathrm{f}}$ implies certain enforcement. Thus, $\operatorname{Pr}(\mathrm{ADD})<1$ needs to be introduced to generate the possibility of diminishing $\mathrm{AD}$ duties under the review process. One can generate a similar result with $\operatorname{Pr}($ TER $)>0$.

${ }^{20}$ Even for the case with multiple stationary equilibria under certain enforcement, the possibility of diminishing AD duties through the review process will emerge with the introduction of uncertainty into the enforcement of $A D$ policy. However, the monotonic relationship between $\operatorname{Pr}(\mathrm{ADD})$ and the possibility of diminishing $\mathrm{AD}$ duties presented in Corollary 1 may fail to hold with the existence of multiple stationary equilibria. The existence of multiple stationary equilibria itself generates an interesting issue as it can create an unstable equilibrium where a small shock initiates a motion to a new equilibrium. This paper, however, will focus on the case of a unique stationary equilibrium.
} 
$\left\{\mathrm{p}_{0}^{\mathrm{di}}, \mathrm{p}_{1}^{\mathrm{di}}, \mathrm{p}_{2}^{\mathrm{di}}, \ldots\right\}$ in Figure $3 \mathrm{a}$, until its price reaches to the stationary equilibrium $\mathrm{p}^{\mathrm{s}}=8$. This implies that the corresponding sequence of $\mathrm{AD}$ duties will approach zero as claimed in Corollary 1 (i).

We can derive similar results to those for ADD in Corollary 1 for the dynamic path of AD duties for TER cases, which follow directly from Proposition 2 (ii). In particular, dumping behavior may lead to better settlement terms for the foreign firm due to competition for export licenses under the settlement, as discussed by Anderson (1992;1993). In this case, a high enough $\operatorname{Pr}($ TER) exists such that the firm would price lower than it would under certain enforcement, and once it becomes subject to AD duties, this effect from the ex ante $\operatorname{Pr}(\mathrm{TER})$ would work toward reducing $\mathrm{AD}$ duties over time.

Figure $3 \mathrm{~b}$ presents an example of this case for specific functional forms. In particular, Figure $3 b$ depicts $G(p)$ for the case where the discount factor is low enough to induce the foreign firm to dump even under certain enforcement, $\mathrm{p}_{0}<\mathrm{p}_{0}^{\mathrm{f}}=8$. In fact, the discount factor is low enough to make $p^{S}(=4)$ below $\underset{P}{\operatorname{Arg} \max }[(p-c) q(p)]=6$, potentially disabling the possibility of having $p_{0}^{E}<p^{S}$, because the lowest optimal value for $p_{0}^{E}$ will be $\underset{P}{\operatorname{Arg} \max }[(p-c) q(p)]=6$ (when $\operatorname{Pr}(\mathrm{ADD})=0)$ if there is no other incentive to reduce the price below the static optimal price. However, a large value for $\operatorname{Pr}\left(\right.$ TER) together with $\mathrm{V}^{\mathrm{T}}(\mathrm{p})$ being strictly decreasing in $\mathrm{p}$ may generate an enough incentive for the foreign firm to cut its price below $\mathrm{p}^{\mathrm{S}}(=4)$ in order to obtain more licenses to export under a possible VER. If $\mathrm{p}_{0}^{\mathrm{E}}$ is set below $\mathrm{p}^{\mathrm{S}}$ due to such a reason as in Figure $3 \mathrm{~b}$, then the pricing path through the review will follow $\left\{\mathrm{p}_{0}^{\mathrm{di}}, \mathrm{p}_{1}^{\mathrm{di}}, \mathrm{p}_{2}^{\mathrm{di}}, \ldots\right\}$ indicated in Figure $3 b$.

Another notable aspect of the numerical example in Figure $3 b$ is that the stationary equilibrium price that the foreign will eventually choose under the $\mathrm{AD}$ enforcement, $\mathrm{p}^{\mathrm{S}}=6$, is lower than the price that it would choose in the absence of any AD policy, $\underset{p}{\operatorname{Arg} \max }[(p-c) q(p)]=6$. This implies that the AD policy with lagged administrative review process may contribute to more aggressive dumping behavior rather than discouraging them. Of course, the AD policy will have the intended impact on dumping behavior for the foreign firms that would not dump if they expect AD duties to follow with certainty, as shown in Proposition 1. For the firms that would dump even under the certain $\mathrm{AD}$ enforcement, however, the lagged 
administrative process can induce those firms to dump more over time, having them dump more excessively than they would in the absence of AD policy.

For most of our empirical work below, we relate percentage changes in the AD duty after the initial case to ex ante probabilities of the outcomes. Denote the initial AD duty when a ADD case occurs by $\mathrm{T}_{0}$ with $\mathrm{T}_{0}=\mathrm{p}_{0}^{\mathrm{f}} / \mathrm{p}_{0}^{\mathrm{E}}$ and the stationary AD duty that will be reached at the end of the administrative review process by $\mathrm{T}_{\mathrm{S}}$ with $\mathrm{T}_{\mathrm{S}}=\mathrm{p}_{0}^{\mathrm{f}} / \mathrm{p}^{\mathrm{S}}$. Following from Proposition 2, then Corollary 2 relates the degree of changes in the AD duty, $\left(T_{S}-T_{0}\right) / T_{0}=\left(p_{0}^{E}-p^{S}\right) / p^{S}$, to the ex ante probabilities, which become our testable hypotheses.

Corollary 2. Given that there exists a unique stationary equilibrium under certain enforcement

i) the increase in the dumping duty through the administrative review process, $\left(\mathbf{p}_{0}^{\mathrm{E}}-\mathbf{p}^{\mathrm{s}}\right) / \mathbf{p}^{\mathrm{s}}$, is increasing in $\operatorname{Pr}(\mathrm{ADD})$,

ii) if $V^{T}(p)$ is strictly decreasing in $p \in\left(c, p_{0}^{f}\right]$, the increase in the dumping duty through the administrative review process, $\left(p_{0}^{E}-p^{s}\right) / p^{s}$, is decreasing in $\operatorname{Pr}(T E R)$, and

iii) if $V^{T}(p)$ is strictly increasing in $p \in\left(c, p_{0}^{f}\right]$, the increase in the dumping duty through the administrative review process, $\left(p_{0}^{E}-p^{s}\right) / p^{s}$, is increasing in $\operatorname{Pr}(T E R)$. (See appendix for proof)

\section{Empirical Methodology}

The previous theoretical section develops a dynamic pricing model for firms facing U.S. AD duties. In this section, we use detailed data from U.S. AD investigations filed during the 1980-1995 period to test the implications presented in Corollary 2; namely, that the increase in the AD duty is increasing in the ex ante probability of an ADD, and could be either decreasing or increasing in the ex ante probability of termination/VER.

A direct test of these implications would use price data. However, data on prices set by the foreign firm are unobservable. Instead, data on $\mathrm{AD}$ duties and changes in these duties from administrative reviews allow us to track pricing decisions by the foreign firms over time in the following way. As described in section 2, the assessed AD duty is the difference between the price of the product exported to the U.S. and some measure of "fair" or "normal" value for the product. Thus, the initial AD duty can serve as a benchmark for the level of the U.S. price relative to this normal value. Over time, administrative reviews of the dumping margin are 
conducted and AD duties are recalculated. The new dumping margin (and, hence, new AD duty) reflects changes in difference between the U.S. price of the product and the measure of normal value. To the extent that these changes in $\mathrm{AD}$ duties over time reflect changes in the U.S. price only, they give a good measure of dynamic changes in U.S. prices after the case from which we can test implications of the previous theoretical section. As discussed earlier, Gallaway et al. (1999) provides evidence that the majority of dumping margin changes stem from changes in the U.S. price, not measures of fair value. On a final note, in the estimation analysis we control for observable instances where the USDOC alters its method of determining fair value.

To examine our hypotheses, we need to relate these foreign firm price changes (reflected in dumping margin changes) to foreign firms' ex ante expectations of an $\mathrm{AD}$ case outcome. To accomplish this we employ a two-step estimation procedure. In the first step, we estimate ex ante probabilities of case outcomes using data on U.S. AD petition filings and outcomes prior to the firm's own case. In the second step, we test whether these estimated ex ante probabilities affect the change in the $\mathrm{AD}$ duty (i.e., change in the firm's U.S. price relative to normal value) that we observe after the case, controlling for other factors. The next subsections provide more detail on each of these estimation steps.

\subsection{First-stage Estimation of Ex Ante Probabilities}

In the first stage, we estimate the ex ante probabilities of various AD case probabilities. These probabilities can be broken into two separate components: The probability that an industry will file an $\mathrm{AD}$ petition and the probabilities of various case outcomes conditional on an AD case petition. For example, the probability that a foreign firm will be subject to an AD case that leads to $\mathrm{AD}$ duties in given year is the probability that the U.S. domestic industry will file a petition multiplied by the probability that the U.S. government will rule affirmative and assess AD duties.

To estimate the unconditional probability of an $\mathrm{AD}$ petition filing, we sample all 4-digit SIC manufacturing industries and use a logit estimation procedure where the dependent variable is " 1 " if a petition is filed in an industry in a given year, and " 0 " otherwise. Then, to estimate the probabilities of $\mathrm{AD}$ case outcomes conditional on a petition being filed, we sample the data from the $\mathrm{AD}$ cases we observe and use a multinomial logit specification where our dependent variable indicates three possible outcomes for an $\mathrm{AD}$ case: 1) affirmative decision with $\mathrm{AD}$ duties, 2) a 
negative decision with no duties imposed, and 3) a termination, withdrawal, or suspension of the case due to a negotiated agreement between the domestic and foreign firms. ${ }^{21,22}$

To estimate ex ante probabilities, we use only the previous years in the sample for both sets of probability estimations (petition probability and case outcome probabilities). For example, to estimate probabilities for 1986 U.S. AD cases in our sample, we use data for only the years from 1980 to 1985 . This assumes that firms do not use information prior to the beginning of our sample in 1980 to form expectations, which may be reasonable since a substantial U.S. AD law change occurred in 1979 that led to a drastic increase in U.S. AD petitions and success rates. However, it also assumes that firms do not have better information than we do to form expectations.

\subsubsection{Petition Probability Estimation Regressors}

For each set of probabilities, we rely on previous literature to specify our explanatory variables. A number of studies have estimated petition probabilities for U.S. manufacturing industries, including Finger (1981), Herander and Schwartz (1984), Feinberg and Hirsch (1989), Hansen (1990), Staiger and Wolak (1994), Krupp (1994), Lichtenberg and Tan (1994), and Furusawa and Prusa (1996). From these studies, import penetration and industry employment (or size) are consistently the variables that explain cross-sectional petition probabilities. The import penetration variables capture how the domestic industry is faring relative to import competitors, which should affect their incentives to file a petition and are criteria used by the USITC in determining injury. The size variable indicates the importance of the industry to the U.S. economy which may affect the USITC's willingness to grant trade protection. Thus, we include the share of imports to domestic consumption and the square of this variable to control for import penetration, as well as employment for the 4-digit SIC industry. We lag these variables one year, as it may take some time for the industry to organize a petition. In addition, the USITC would look at economic conditions up to three years prior to the petition in

21 Below we discuss sensitivity of results to alternative categorizations of AD case outcomes.

22 An alternative procedure would be estimation of our ex ante probabilities through a nested logit specification. The advantage of a nested logit specification is that it would capture the possibility that the petition probabilities may not be independent of the case outcome probabilities. However, a standard nested logit specification assumes a choice structure where characteristics of the alternative paths are the explanatory variables for a particular type of decision maker. Our problem here is different in important ways. First, there are different decision makers at each stage: The domestic industry in the first stage petition decision and government agencies in the second stage case 
determining the eventual outcome of the case. ${ }^{23}$ We expect import penetration to positively affect the probability of an AD petition, with the quadratic term potentially negative in sign, and employment to be positively related to petition probability. Unlike previous studies, we also include a variable that indicates whether the industry has filed an AD petition previously. We expect a positive relationship between this variable and petition probability, since familiarity with the $\mathrm{AD}$ petitioning process would presumably lower costs of future petitions. There may be a number of time-invariant industry characteristics that would affect petition filings, such as those that would influence the ability of the industry to organize and jointly support an AD petition. To control for these characteristics, we estimate a random effects specification of our logit model. Finally, to control for macroeconomic shocks that may affect petition filing we follow Knetter and Prusa (2000) and include GDP growth and the exchange rate (a multilateral index of the U.S. exchange rate in terms of foreign currency per dollar). ${ }^{24}$

\subsubsection{AD Case Outcome Probability Estimation Regressors}

A number of empirical papers have examined the factors that determine the injury determination by the USITC which, in turn, largely determines whether a U.S. AD case will be ruled affirmative or negative. These studies include Finger, Hall and Nelson (1982), Baldwin (1985), Moore (1992), DeVault (1993), and Hansen and Prusa (1996,1997). Determinants of withdrawn/suspended cases are estimated by Zanardi (2000). We draw on these studies for specifying our matrix of explanatory variables, $\mathrm{X}_{\mathrm{ij}}$.

First, the economic factors that determine the USITC injury decision play a large role whether the USITC rules affirmative in the case. As with petition filing probability estimation, we include the share of imports to domestic consumption and the square of this variable to control for import penetration, and industry employment for the 4-digit SIC industry. We expect greater import penetration and higher industry employment to increase the likelihood of affirmative and terminated/suspended outcomes. However, as Zanardi (2000) points out, AD cases are more likely to lead to settlements (rather than AD duties) when they involve products

outcome decision. Second, our explanatory variables are case-specific and industry-specific, not path-specific. In other words, they do not vary by the alternative (i.e., case outcome) that is "chosen".

${ }^{23}$ Knetter and Prusa (2000) make this point as well. They also lag these variables one year in their estimation of country-level AD petition filings and find no qualitative difference when they use three-year lags.

${ }^{24}$ A more general way of controlling for macroeconomic effects would be year dummies. However, we found inclusion of these were marginally insignificant at standard confidence levels. 
with substantial interest to the U.S. government. This suggests that cases may more likely lead to settlements once the trade volume and/or employment size of the industry becomes substantial.

One problem with using 4-digit SIC industry data is that it may not match very well the more narrowly defined products involved in $\mathrm{AD}$ cases. We are able to gather information from the specific AD cases import volumes of the investigated product. Thus, we include these import volumes and import volumes squared, expecting positive and negative coefficients, respectively. $^{25}$

Non-economic factors have been found to affect AD case outcomes in these studies as well. Many studies have found that certain regions are more likely to receive certain outcomes than others. Studies on USITC decisions find that cases against EU countries are more likely to receive a negative outcome, while cases against Japan and non-market economies are more likely to receive affirmative outcomes. Zanardi (2000) finds that EU and non-market countries are more likely to have settled cases. We include region dummies for the EU, non-market countries, Japan, Asian NICs, and less-developed countries.

Another common focus is whether steel and steel-related industries receive different outcomes, everything else, because so many U.S. AD cases cover these products and they were often high profile trade disputes. The USITC studies often find these industries are more likely to receive affirmative decisions. Also, a disproportionate number appear to end with settlements/VERs as well, though Zanardi (2000) does not find a statistically significant steel effect. We include variables to capture industry effects for steel (SIC 3312, 3313, and 3315) and steel pipes and tubes (SIC 3317). ${ }^{26,27}$ Another industry control we include is the 4-firm concentration ratio.

As with petition filing, past outcomes may correlate with current outcomes, including learning on the part of the petitioners and government agencies. Thus, we include three separate dummy variables indicating whether a product has been involved in a previous affirmative U.S.

\footnotetext{
${ }^{25}$ Import penetration for the investigated product, rather than simply import volumes, would obviously be a preferred variable. However, domestic shipment data of the investigated product is often suppressed from USITC reports accompanying the $\mathrm{AD}$ case.

${ }^{26}$ There may be reasons to include year dummies in this estimation stage, but in a number of years there are only one or zero instances of a particular case outcome (particularly terminated/suspended) which leads to collinearity problems with including year dummies.

${ }^{27}$ With the exception of steel products, AD cases cover a wide variety of industries with often only a few cases in a particular industry, making it difficult to include systematic industry dummies.
} 
AD outcome, a negative U.S. AD outcome, or a terminated/suspended U.S. AD outcome. Finally, we include GDP growth and exchange rates to control for macroeconomic conditions.

\subsection{Second-stage Estimation of Dumping Margin Changes}

In the second stage, the focus of our empirical analysis, we sample all firm and product combinations that were subject to an affirmative U.S. AD decision during our sample and examine whether changes in the dumping duties subsequent to the case are related to the ex ante unconditional $\mathrm{AD}$ case outcome probabilities estimated in the first stage. As discussed, dumping margins change through administrative reviews, which can be initiated every year at the anniversary date of the initial AD orders. Since these reviews can take a number of years to be completed in practice, we specify our dependent variable as the percentage change (in decimal form) in the $\mathrm{AD}$ duty four years subsequent to the case. This time period is long enough so that firms that initiated administrative reviews had experienced at least one change in the AD duty since the time of the case. A significant number of margins (83 or $15 \%)$ were reduced to zero during this time period, which means a lower bound of -1 . For this reason, we use a tobit specification truncated at -1 . As a sensitivity check, we also report results for a probit specification where the dependent variable indicates whether the dumping margin stays the same (or increases) after the case or not.

Our main regressors are the estimated unconditional probabilities of an affirmative and terminated/suspended probabilities estimated in the first stage. These are the conditional probabilities of affirmative and terminated/suspended probabilities multiplied by the probability of petition. We exclude the unconditional probability of a negative decision to avoid perfect collinearity, as the three unconditional probabilities necessarily sum to one for each observation. Below we also discuss further controls in this regression that we add after first presenting results for this most basic regressor matrix.

One significant concern with this specification is that the regressors are generated from previous regressions. This can lead to biased standard errors, as shown by Pagan (1984). Since there is no available formula for the covariance matrix when one introduces probabilities from a logit and multinomial logit estimations into a tobit equation, we use bootstrap methods to generate standard errors in this second stage estimation. 


\section{Data}

Our sample for the first stage estimates of the AD petition probabilities consists of data for all 4-digit SIC (1972-revision 2) U.S. manufacturing industries from 1980 and 1994. Data on U.S. AD petitions and investigated tariff-line codes were collected from Federal Register notices and concorded to 4-digit SIC using the NBER Trade Database developed by Robert Feenstra. Imports from this same source were combined with 4-digit SIC level shipment data from the NBER Manufacturing Industry Productivity Database developed by Bartelsman, Becker and Gray, to construct the import penetration variables. Industry employment data also come from this latter NBER database. GDP growth and a trade-weighted multilateral index of the dollar (in terms of foreign currency per U.S. dollar) comes from the Economic Report of the President.

Our sample for the first stage estimates of the AD case outcome probabilities consists of all U.S. AD manufacturing cases filed between 1980 and 1994. Data on the cases and AD decisions were collected from Federal Register notices. We define terminated/VER cases as only those where a VER or other formal settlement is publicly announced, and classify other withdrawn or terminated cases as negative outcomes. Below, we present results when we categorize these cases in an alternative manner. Thus, of the 715 case determinations for which we have observable data, $296(41 \%)$ are categorized as affirmative, 338 (48\%) are categorized as negative, and the remaining $81(11 \%)$ are categorized as terminated/VER. Industry data on import penetration and employment come from the same sources as indicated above. Import volumes for the particular products involved in the case were taken from USITC reports and estimated when not available by collecting trade volumes of the subject tariff line codes from the NBER Trade Database. Concentration ratio data at the 4-digit SIC level are for the year 1987 and come from the Census of Manufactures. Table 1 gives the descriptive statistics for the variables we use in our first-stage estimations for the entire sample from 1980 through 1994 for both the logit estimates of petition probabilities and the multinomial regressions of AD case outcomes. $^{28}$

Our sample for the second stage estimates consists of all manufacturing firm-product combinations subject to U.S. affirmative AD decisions and AD duties for U.S. AD investigations filed between 1980 and 1995. Much of the data were initially collected by James DeVault from Federal Register notices and USITC reports connected with each case (See DeVault, 1996, for 
more details on data collection). Information available from these data sources includes firmspecific AD duties both at the time of the initial case, and in subsequent administrative reviews. As discussed, these $\mathrm{AD}$ duties are estimated dumping margins and reflect differences in the firm's U.S. price and a definition of "normal" value, which is often the foreign firm's price in its home market. The evidence from our sample is that there is substantial variation in AD duty changes from administrative review. Out of the 541 firm-specific initial AD duties in our sample, 254 (47.0\%) were subsequently reviewed at least once. ${ }^{29}$ The average change in the AD duty after the first administrative review is from $41.3 \%$ to $31.4 \%$, a sizeable decrease. However, there were 34 cases $(6.3 \%)$ where the $\mathrm{AD}$ duty increased after the first administrative review.

\section{Empirical Results}

\subsection{First-stage Estimates of Ex Ante Probabilities}

In the first stage we perform both random effect logit estimations of the petition probability and multinomial logit estimates of the $\mathrm{AD}$ case outcomes. For both sets of estimations, we estimate separate regressions for each year from 1982 through 1995 using the data from previous years back to 1980 in order to construct ex ante probabilities of AD case outcomes for our second stage. ${ }^{30}$ For the sake of space, table 2 and 3 present coefficient estimates from three of the thirteen subsamples in the estimations for petition and AD case outcome probabilities, respectively. In other words, we present estimates used to construct ex ante probabilities for years 1985, 1990 and 1995, using subsamples 1980-1984, 1980-1989, and 1980-1994, respectively. For the multinomial logit estimations of AD case outcomes, we normalize the coefficient estimates for a negative AD outcome to be one, in order to identify and, hence, estimate the parameters of the model. Thus, table 3 gives coefficient estimates for affirmative and terminated/VER outcomes, which are interpreted as effects relative to the negative outcome.

Both sets of regressions in tables 2 and 3 show decent fit of the data even for the earlier 1985 subsample we report, though a greater number of variables are correct sign and statistically

\footnotetext{
${ }^{28}$ Many of the U.S. AD data used for this study can be found at the following webpage developed by Bruce Blonigen: http://darkwing.uoregon.edu/ bruceb/adpage.html.

${ }^{29}$ Two outliers were eliminated that involved very small initial AD margins with modest percentage point increases that translated into extremely large percentage increases. Elimination of these two outliers does not affect our results qualitatively, but led to more reasonable coefficient magnitudes and increased the $\mathrm{R}^{2}$ measures by an order of magnitude.

30 Reasonably estimated ex ante probabilities for 1981 were not possible because of insufficient sample size.
} 
significant for later samples. ${ }^{31}$ For the sake of space, we do not describe the specific details of the coefficient estimates. However, we note that the estimated probabilities seem quite reasonable. For example, the average estimated ex ante probabilities of case outcomes almost exactly match the actual sample average probabilities.

\subsection{Second-stage Estimates - Testing Implications of Corollary 1 and 2}

Using the coefficient estimates from the first stage, we construct predicted ex ante probabilities of affirmative and terminated/VER AD outcomes to be used as regressors to test the implications of Corollary 1 and 2. Obviously, the constructed probabilities are for only the 541 firm-product combinations that became subject to affirmative $\mathrm{AD}$ decisions and, hence, $\mathrm{AD}$ duties. Column 1 of table 4 reports estimates from tobit estimates where the dependent variable is the 4-year percentage change in the dumping margin after the case and the regressors are a constant and the predicted probabilities of affirmative and terminated/VER outcomes. The chisquared statistic easily rejects the null hypothesis of jointly zero slopes at the 1 percent level.

The coefficient on the ex ante probability of termination/VER is negative and statistically significant at the 1 percent level. This empirical result corresponds with the case in Corollary 2 where $\mathrm{V}^{\mathrm{T}}(\mathrm{p})$ is strictly decreasing in $\mathrm{p}$; in other words, the case that is consistent with firm behavior when Anderson's domino dumping scenario is relevant. The coefficient magnitude in this case is likewise substantial. At the means, a standard deviation increase in the ex ante termination/VER probability (13.7 percentage points) means an additional 37.7 percentage point decrease in the $\mathrm{AD}$ duty. This is large, given an average $24.0 \%$ decline in the $\mathrm{AD}$ duty in our sample. The incorrect and statistically insignificant coefficient on the ex ante probability of an affirmative outcome fails to confirm the first part of Corollary 2. However, as we next show, this insignificant result is due to omitted variable bias.

In particular, a potential concern with these estimates is that the USDOC often changes the way it measures normal value from the time of the case to subsequent administrative reviews. This could have a substantial effect on the dumping margin over time, even if the foreign firm did not alter its pricing policies and could seriously bias our estimates if it is not properly

\footnotetext{
${ }^{31}$ As an alternative, we estimated our "ex ante" probabilities using the full sample for every observation, rather than only previous-year subsamples. This might be warranted if firms early in the sample could anticipate petition probabilities and case outcome probabilities better than our model using only previous years. However, when we use the full-sample estimates to construct ex ante probabilities we get qualitatively similar coefficient estimates in our second-stage regression analysis.
} 
accounted for in our estimation. The most substantial of these rule changes is when the USDOC uses "best information available" (BIA), because then the USDOC uses information supplied by the petitioners rather than the foreign firms. ${ }^{32}$ Specifically, we include a dummy variable when the original margin calculation was calculated using BIA at the time of the case, but not during the subsequent administrative review. We also include a dummy variable for the reverse case, where BIA was not used at the time of the case, but then used for the administrative review. A related concern is the USDOC's handling of non-market economies where price data may not exist. This allows the USDOC to use a variety of methods to estimate dumping margins. In addition, firms from non-market economies may not be profit-maximizing which is an essential assumption of our theory. Thus, we include a dummy variable indicating observations that involve non-market economies.

A second concern is that from 1980-1984 administrative reviews occurred automatically each year at the anniversary of the case, whereas after 1984 these reviews occurred only if an interested party (a foreign or domestic firm involved in the case) requested a review. This structural change in the law may also alter the dumping margin changes that we observe. We add a number of control variables to account for these administrative changes connected with USDOC dumping margin calculations. To control for this we include a dummy variable for any cases that occurred when administrative reviews were automatic, rather than only initiated upon the request of an interested party.

A final concern is that a number of cases were revoked within the four-year window on which we focus. We record these as cases where the AD duty decreased 100 percent under the rationale that revocations occur because the foreign firm completely reduced its $\mathrm{AD}$ duty. However, revocations may occur for a variety of alternative reasons which may not be due to any change on the part of the foreign firm. Thus, we include a dummy variable indicating cases which were revocations of the $\mathrm{AD}$ duties, not changes due to standard administrative reviews.

Column 2 of table 4 presents results of our second stage estimates when we include these additional controls. All five additional control variables are statistically significant at standard confidence levels and the pseudo $\mathrm{R}^{2}$ increases substantially. The positive coefficient on the second control variable ("Change from no BIA to BIA") is as expected, since the USDOC switching to information from the domestic petitioners to calculate dumping margins should lead

\footnotetext{
${ }^{32}$ Another practice often used by USDOC is constructed cost measures to rule out foreign home prices (used to
} 
to more adverse dumping duties. By the same rationale, though, the coefficient on the first additional control ("Change from BIA to no BIA") is expected to be negative, but is positive. We note, however, that the coefficient on this variable is much smaller and more imprecisely estimated than for the second control variable. The coefficient on automatic administrative reviews is negative. One possible explanation for this is that once administrative reviews were no longer automatic, foreign firms now had to incur substantial costs to request administrative reviews which led to less firms choosing to reduce dumping and receive a review. Finally, our estimates suggest that non-market economies are less likely to have AD duties fall, while revocations lead to substantially larger decreases in the AD duty, as expected.

Importantly, controlling for these additional variables leads to a statistically significant positive coefficient on the ex ante probability of an affirmative outcome, confirming our hypothesis in Corollary 2. The coefficient estimate is also economically significant, as it suggests that a standard deviation in the ex ante probability of an affirmative outcome (7.2 percentage points) implies only a $18.2 \%$ drop in the $\mathrm{AD}$ duty at the means, rather than the average $24.0 \%$ decline. The ex ante probability of a terminated/VER outcome falls by about half, but continues to be statistically and economically significant.

We also tried a number of alternative specifications to check the sensitivity of our results. First, in the initial specifications, we took a strict definition of terminated/VER cases, in the sense that we included only those cases where VERs or settlements were publicly announced. Any other withdrawn or terminated cases were treated as negative outcomes for our estimation of the ex ante probabilities. However, as indicated by Prusa (1992), many withdrawn cases may be due to private settlements that yield similar outcomes for the involved firms. Thus, as an alternative we categorized all such cases as terminated/VER cases, rather than negative outcomes. Tobit estimates using ex ante probabilities generated from this alternative categorization are shown in column 3 of table 4 . Results are qualitatively similar to those in column 2 of table 4, though the coefficient on the terminated/VER probability falls to less than one-quarter the magnitude in column 2 and is imprecisely estimated. This change in definition leads to lower fit for the regression in general. This may suggest that it is improper to include these withdrawn cases with no publicly announced settlements as ones where a public settlement

determine fair value) as below cost. 
was reached or, alternatively, private settlements may not elicit the same pricing behavior induced by "domino dumping" that our results suggest are occurring with public settlements. ${ }^{33}$

To test the version of our hypotheses in Corollary 1 (and also as another sensitivity check), we substituted a dummy variable that takes the value of "1" if the AD duty does not decline (either increases or stay the same) after the AD case for our dependent variable and estimated the coefficients using a standard probit model. These estimates are reported in column 4 of table 4. The coefficient on ex ante probability of an affirmative outcome is once again statistically and economically significant in this specification. The coefficient estimate on $e x$ ante probability of terminated/VER outcome suggests marginal economic effects in line with the tobit estimates, but is more imprecisely estimated with the probit specification. However, we note our reported boot-strapped standard errors assume normality. When we boot strap biascorrected confidence intervals, both the ex ante affirmative and terminated/VER probabilities are statistically significant at the $95 \%$ confidence level in this probit specification.

\section{Concluding Remarks}

Our theoretical model under certain enforcement of AD trade policy can explain what are seemingly unreasonable behaviors of foreign firms subject to AD duties: Not all the foreign firms try to take advantage of the administrative review process by raising their export prices to lower $\mathrm{AD}$ duties. For the firms that choose to dump in the initial period, despite $\mathrm{AD}$ duties in the following period, the presence of $\mathrm{AD}$ duties will make the inter-temporal tradeoff between the current and the future discounted profits more favorable to dumping behavior in the next period, yielding constant or higher $\mathrm{AD}$ duties through the review process. Introducing uncertain enforcement of $\mathrm{AD}$ trade policy into our model reveals incentives for the foreign firms to reduce their $\mathrm{AD}$ duties through the review process. Once a foreign firm is subject to $\mathrm{AD}$ duties the firm may adjust its prices so that $\mathrm{AD}$ duties fall over time in subsequent reviews, depending on its $e x$ ante expectations and discount rate.

The empirical results support the theoretical model with uncertain enforcement by showing that a lower ex ante probability of $\mathrm{AD}$ duties correlates with a greater reduction in $\mathrm{AD}$ duties in the administrative review after controlling for USDOC procedural idiosyncrasies. The

\footnotetext{
${ }^{33}$ Taylor (2001) finds no evidence that withdrawn cases lead to market outcomes that suggest private collusive settlements.
} 
empirical results also find the first systematic empirical evidence of behavior consistent with Anderson's (1992;1993) well-known domino dumping model. In Anderson's model, firms with ex ante expectations that an antidumping investigation will likely lead to a settlement dump more in anticipation of VER rents based on export market share. Our model, in turn, shows that when such firms then receive $\mathrm{AD}$ duties instead of a settlement their increase in prices in subsequent periods to reduce those AD duties will be more substantial. Our empirical results support this scenario by finding that a higher ex ante expectation of terminated/VER outcome substantially lowers $\mathrm{AD}$ duties in subsequent periods, all else equal.

There are various ways to extend the current theoretical model, which could also lead to further empirical analysis. We can study how different types of uncertainties, like fluctuations in exchange rates or in product demands, affect firms' dynamic pricing under AD trade policy. We can also analyze how the vertical relationship between a foreign exporter and a domestic importer may affect the foreign firm's dynamic pricing path. These theoretical extensions may generate a new set of testable predictions on dynamic pricing of firms subject to $\mathrm{AD}$ duties. 


\section{Appendix}

\section{Proof for Lemma 1.}

We can directly apply Theorem 4.6 in Stokey et al. (1989) to prove Lemma 1. Denote the domain of the prices that the foreign firm can choose from by $\mathrm{P}$, and let $\Gamma: \mathrm{P} \rightarrow \mathrm{P}$ be the correspondence describing the feasibility constraints, following Stokey et al. Thus, for each $p \in$ $\mathrm{P}, \Gamma(\mathrm{p})$ is the set of feasible values for the state variable in the next period if the current state is $\mathrm{p}$. To apply Theorems 4.6, we need to show that

i) $\mathrm{P}$ is a convex subset of $\mathrm{R}$, and the correspondence $\Gamma: \mathrm{P} \rightarrow \mathrm{P}$ is nonempty, compact-valued, and continuous.

ii) The function $\left(\mathrm{p}_{\mathrm{t}}-\mathrm{c}\right) \cdot \mathrm{q}\left(\mathrm{p}_{\mathrm{t}} \cdot \mathrm{T}_{\mathrm{t}}\left(\mathrm{p}_{\mathrm{t}-1}\right)\right): \mathrm{A} \rightarrow \mathrm{R}$ is bounded and continuous, where $\mathrm{A}=$ $\left\{\left(\mathrm{p}_{\mathrm{t}-1}, \mathrm{p}_{\mathrm{t}}\right) \in \mathrm{P} \times \mathrm{P}: \mathrm{p}_{\mathrm{t}} \in \Gamma\left(\mathrm{p}_{\mathrm{t}-1}\right)\right\}$.

(i) Without loss of generality, we can define $P$ to be $[0, \bar{p}]$. This is because the effect of setting $p$ $>\bar{p}$ is identical to that of setting $\mathrm{p}=\overline{\mathrm{p}}$ : both actions will eliminate current period sales and reduce the next period $A D$ duty to zero $(T(p)=1)$ given $\bar{p} \geq p_{0}^{f}$. Then, $\Gamma(p)$ is $[0, \bar{p}]$ for all $p \in$ $[0, \overline{\mathrm{p}}]$, satisfying (i).

(ii) Because $\mathrm{q}\left(\mathrm{p}^{\mathrm{c}}\right)=0$ when $\mathrm{p}^{\mathrm{c}} \rightarrow \infty$ and $\mathrm{q}\left(\mathrm{p}^{\mathrm{c}}\right)$ is bounded, $\left(\mathrm{p}_{\mathrm{t}}-\mathrm{c}\right) \cdot \mathrm{q}\left(\mathrm{p}_{\mathrm{t}} \cdot \mathrm{T}_{\mathrm{t}}\left(\mathrm{p}_{\mathrm{t}-1}\right)\right)$ is also a bounded function in $\mathrm{A}$. Because multiplication of continuous functions generates a continuous function, $\left(\mathrm{p}_{\mathrm{t}}-\mathrm{c}\right) \cdot \mathrm{q}\left(\mathrm{p}_{\mathrm{t}} \cdot \mathrm{T}_{\mathrm{t}}\left(\mathrm{p}_{\mathrm{t}-1}\right)\right)$ is also a continuous function.

\section{Proof for Lemma 2.}

We can use a similar argument as in Theorem 4.7 of Stokey et al. (1989) to show that $\mathrm{V}\left(\mathrm{p}_{-1}\right)$ is a strictly increasing function on $\mathrm{p}_{-1} \in\left[\mathrm{c}, \mathrm{p}_{0}^{\mathrm{f}}\right)$. To directly apply the theorem to lemma 2, (i) $\Gamma(\mathrm{p}) \subseteq \Gamma\left(\mathrm{p}^{\prime}\right)$ if $\mathrm{p} \leq \mathrm{p}^{\prime}$ and (ii) $\left(\mathrm{p}_{\mathrm{t}}-\mathrm{c}\right) \cdot \mathrm{q}\left(\mathrm{p}_{\mathrm{t}} \cdot \mathrm{T}_{\mathrm{t}}\left(\mathrm{p}_{\mathrm{t}-1}\right)\right)$ is a strictly increasing function in $\mathrm{p}_{\mathrm{t}-1}$ $\in\left[c, p_{0}^{f}\right)$ for every $p_{t} \in[0, \bar{p}]$ need to be satisfied. (i) is satisfied because $\Gamma(p) \equiv \Gamma\left(p^{\prime}\right) \equiv[0, \bar{p}]$, but $\left(p_{t}-c\right) \cdot q\left(p_{t} \cdot T_{t}\left(p_{t-1}\right)\right)$ is not increasing in $p_{t-1}$ when $p_{t}<c$. However, we can still show that $\mathrm{V}\left(\mathrm{p}_{-1}\right)$ is a strictly increasing function as follows.

Define the operator $S$ on $C(P)$, a space of bounded continuous functions $f: P \rightarrow R$ with the sup norm, by $(\mathrm{Sf})\left(\mathrm{p}_{-1}\right)=\underset{\mathrm{p} \in \Gamma\left(\mathrm{p}_{-1}\right)}{\operatorname{Max}}\left[(\mathrm{p}-\mathrm{c}) \mathrm{q}\left(\mathrm{p} \cdot \mathrm{T}\left(\mathrm{p}_{-1}\right)\right)+\delta \cdot \mathrm{f}(\mathrm{T}(\mathrm{p}))\right]$. From lemma 1, we know that the operator $\mathrm{S}$ maps $\mathrm{C}(\mathrm{P})$ into itself, $\mathrm{S}: \mathrm{C}(\mathrm{P}) \rightarrow \mathrm{C}(\mathrm{P})$ and $\mathrm{S}$ has a unique fixed point $\mathrm{V}\left(\mathrm{p}_{-1}\right) \in$ $\mathrm{C}(\mathrm{P})$. Define $\mathrm{C}^{\prime}(\mathrm{P})$ to be a space of bounded, continuous, and non-decreasing functions $\mathrm{g}: \mathrm{P} \rightarrow \mathrm{R}$ with the sup norm. $\mathrm{C}^{\prime}(\mathrm{P})$ is a closed subset of $\mathrm{C}(\mathrm{P})$, thus if $\mathrm{S}\left(\mathrm{C}^{\prime}\right) \subseteq \mathrm{C}^{\prime \prime}(\mathrm{P})$, a space of bounded continuous and strictly increasing function, then $V\left(p_{-1}\right) \in C^{\prime \prime}(P)$ according to Corollary 1 to Theorem 3.2 (Contraction Mapping Theorem) in Stockey et al. Thus, it remains to show that $\mathrm{S}\left(\mathrm{C}^{\prime}\right) \subseteq \mathrm{C}^{\prime \prime}$. Because $\mathrm{S}\left(\mathrm{C}^{\prime}\right)$ is already been shown to be bounded and continuous, we only need to show that $(\operatorname{Sg})\left(\mathrm{p}_{-1}\right)=\underset{\mathrm{p} \in \Gamma\left(\mathrm{p}_{-1}\right)}{\operatorname{Max}}\left[(\mathrm{p}-\mathrm{c}) \cdot \mathrm{q}\left(\mathrm{p} \cdot \mathrm{T}\left(\mathrm{p}_{-1}\right)\right)+\delta \cdot \mathrm{g}(\mathrm{p})\right]$ is strictly increasing in $\mathrm{p}_{-1} \in\left[\mathrm{c}, \mathrm{p}_{0}^{\mathrm{f}}\right)$. We can confine our attention to $g(p)$ with $g(p)=g\left(p_{0}^{f}\right)$ for $p \geq p_{0}^{f}$ w.l.o.g. because $V(p)=V\left(p_{0}^{f}\right)$ for $\mathrm{p} \geq \mathrm{p}_{0}^{\mathrm{f}}$ as $\mathrm{T}(\mathrm{p})=1$ for all $\mathrm{p} \geq \mathrm{p}_{0}^{\mathrm{f}}$. First, note that $\mathrm{p}$ will be chosen such that $\mathrm{q}\left(\mathrm{p} \cdot \mathrm{T}\left(\mathrm{p}_{-1}\right)\right)>0$. Consider setting $\mathrm{p}=\mathrm{p}^{\prime}$ with $\mathrm{q}\left(\mathrm{p}^{\prime} \cdot \mathrm{T}\left(\mathrm{p}_{-1}\right)\right)=0$. Given $(\mathrm{A} 3)$ and $\mathrm{p}_{-1} \in\left[\mathrm{c}, \mathrm{p}_{0}^{\mathrm{f}}\right], \mathrm{q}\left(\mathrm{p}^{\prime} \cdot \mathrm{T}\left(\mathrm{p}_{-1}\right)\right)=0$ 
implies that $\mathrm{p}^{\prime}>\mathrm{p}_{0}^{\mathrm{f}}$. Because $\left(\mathrm{p}_{0}^{\mathrm{f}}-\mathrm{c}\right) \cdot \mathrm{q}\left(\mathrm{p}_{0}^{\mathrm{f}} \cdot \mathrm{T}\left(\mathrm{p}_{-1}\right)\right)+\delta \cdot \mathrm{g}\left(\mathrm{p}_{0}^{\mathrm{f}}\right)>\delta \cdot \mathrm{g}\left(\mathrm{p}^{\prime}\right), \mathrm{p}=\mathrm{p}^{\prime}$ with $\mathrm{q}\left(\mathrm{p}^{\prime} \cdot \mathrm{T}\left(\mathrm{p}_{-1}\right)\right)=0$ will not be chosen as $\mathrm{p}=\mathrm{p}_{0}^{\mathrm{f}}$ is a strictly dominating choice. Also note that $\mathrm{p} \leq \mathrm{c}$ will not be chosen. Consider setting $\mathrm{p}=\mathrm{p}^{\prime} \leq \mathrm{c}$, thus having $\left(\mathrm{p}^{\prime}-\mathrm{c}\right) \cdot \mathrm{q}\left(\mathrm{p}^{\prime} \cdot \mathrm{T}\left(\mathrm{p}_{-1}\right)\right) \leq 0$. Given (A4) and $\mathrm{p}_{-1} \in\left[\mathrm{c}, \mathrm{p}_{0}^{\mathrm{f}}\right]$, it is possible to set $\mathrm{p}=\mathrm{p}^{\prime \prime}=\mathrm{c}+\varepsilon$ with $\varepsilon>0$, so that $\left(\mathrm{p}^{\prime \prime}-\mathrm{c}\right) \cdot \mathrm{q}\left(\mathrm{p}^{\prime \prime} \cdot \mathrm{T}\left(\mathrm{p}_{-1}\right)\right)>0$. As $\mathrm{p}^{\prime \prime}>\mathrm{p}^{\prime}$ and $\mathrm{g} \in \mathrm{C}^{\prime}$, this implies that $\left(\mathrm{p}^{\prime \prime}-\mathrm{c}\right) \cdot \mathrm{q}\left(\mathrm{p}^{\prime \prime} \cdot \mathrm{T}\left(\mathrm{p}_{-1}\right)\right)+\delta \cdot \mathrm{g}\left(\mathrm{p}^{\prime \prime}\right)>\left(\mathrm{p}^{\prime}-\mathrm{c}\right) \cdot \mathrm{q}\left(\mathrm{p}^{\prime} \cdot \mathrm{T}\left(\mathrm{p}_{-1}\right)\right)+$ $\delta \cdot g\left(p^{\prime}\right)$. Having established that $p>c$ and $q\left(p \cdot T\left(p_{-1}\right)\right)>0$ in solving $(\operatorname{Sg})\left(p_{-1}\right)$ $=\underset{\mathrm{p} \in \Gamma\left(\mathrm{p}_{-1}\right)}{\operatorname{Max}}\left[(\mathrm{p}-\mathrm{c}) \cdot \mathrm{q}\left(\mathrm{p} \cdot \mathrm{T}\left(\mathrm{p}_{-1}\right)\right)+\delta \cdot \mathrm{g}(\mathrm{p})\right]$, we can easily show that $\mathrm{S}\left(\mathrm{C}^{\prime}\right) \subseteq \mathrm{C}^{\prime \prime}$. For $\mathrm{p}$ solving $(\operatorname{Sg})\left(\mathrm{p}_{-1}\right), \partial\left[(\mathrm{p}-\mathrm{c}) \cdot \mathrm{q}\left(\mathrm{p} \cdot \mathrm{T}\left(\mathrm{p}_{-1}\right)\right)+\delta \cdot \mathrm{g}(\mathrm{p})\right] / \partial \mathrm{p}_{-1}=-(\mathrm{p}-\mathrm{c}) \cdot\left(\partial \mathrm{q}\left(\mathrm{p} \cdot \mathrm{T}\left(\mathrm{p}_{-1}\right)\right) / \partial \mathrm{p}^{\mathrm{c}}\right) \cdot\left(\mathrm{p} \cdot \mathrm{p}_{0}^{\mathrm{f}} / \mathrm{p}_{-1}^{2}\right)>0$ for $\mathrm{p}_{-1} \in\left[\mathrm{c}, \mathrm{p}_{0}^{\mathrm{f}}\right)$ because $\mathrm{p}>\mathrm{c}$ and $\partial \mathrm{q}\left(\mathrm{p} \cdot \mathrm{T}\left(\mathrm{p}_{-1}\right)\right) / \partial \mathrm{p}^{\mathrm{c}}<0$ with $\mathrm{q}\left(\mathrm{p} \cdot \mathrm{T}\left(\mathrm{p}_{-1}\right)\right)>0$. This implies that $\mathrm{S}\left(\mathrm{C}^{\prime}\right) \subseteq \mathrm{C}^{\prime \prime}$ for $\mathrm{p}_{-1} \in\left[\mathrm{c}, \mathrm{p}_{0}^{\mathrm{f}}\right)$.

Now, we can narrow down the economically relevant domain and image of $G(p)$ as follows. First, it is easy to establish that we can focus on the optimal pricing path where $\mathrm{p}_{\mathrm{i}}>\mathrm{c}$ for $i=0,1,2, \ldots$ w.l.o.g., if the foreign firm chooses its initial price $p_{0}$ in the absence of $A D$ duties $\left(\mathrm{T}_{0}=1\right)$. As shown above, any $\mathrm{p}=\mathrm{p}^{\prime} \leq \mathrm{c}$ is strictly dominated by some $\mathrm{p}=\mathrm{p}^{\prime \prime}>\mathrm{c}$ in solving $(\operatorname{Sg})\left(\mathrm{p}_{-1}\right)=\underset{\mathrm{p} \in \Gamma\left(\mathrm{p}_{-1}\right)}{\operatorname{Max}}\left[(\mathrm{p}-\mathrm{c}) \cdot \mathrm{q}\left(\mathrm{p} \cdot \mathrm{T}\left(\mathrm{p}_{-1}\right)\right)+\delta \cdot \mathrm{g}(\mathrm{p})\right]$ when $\mathrm{p}_{-1} \geq \mathrm{c}$, and the same is true when $\mathrm{g}(\mathrm{p})=\mathrm{V}(\mathrm{p})$. This implies that $\mathrm{G}(\mathrm{p})>\mathrm{c}$ for $\mathrm{p} \geq \mathrm{c}$, thus optimal pricing path will involve prices strictly greater than $\mathrm{c}$.

We show that the optimal pricing path involves prices equal or less than $\mathrm{p}_{0}^{\mathrm{f}}$ as follows. Note that we only need to consider the optimal pricing path with positive sales. Consider the case where the firm chooses $\mathrm{p}_{0}>\mathrm{p}_{0}^{\mathrm{f}}$ in the initial period. This cannot be a part of optimal pricing path because setting $\mathrm{p}_{0}^{\prime}=\mathrm{p}_{0}^{\mathrm{f}}$ will strictly raise the discounted payoff, $\left(\mathrm{p}_{0}^{\prime}-\mathrm{c}\right) \cdot \mathrm{q}\left(\mathrm{p}_{0}^{\prime}\right)+$ $\mathrm{V}\left(\mathrm{p}_{0}^{\prime}\right)>\left(\mathrm{p}_{0}-\mathrm{c}\right) \cdot \mathrm{q}\left(\mathrm{p}_{0}\right)+\mathrm{V}\left(\mathrm{p}_{0}\right)$. Because (A4) is a sufficient condition for $2 \times \partial \mathrm{q}\left(\mathrm{p}^{\mathrm{c}}\right) / \partial \mathrm{p}^{\mathrm{c}}+\left(\mathrm{p}^{\mathrm{c}}-\right.$ c) $\cdot\left(\partial^{2} q\left(p^{c}\right) / \partial p^{c 2}\right)<0$ (the second order condition for static profit maximization with $\mathrm{T}=1$ ) as long as $\mathrm{p}^{\mathrm{c}}>\mathrm{c}$ and $\mathrm{q}\left(\mathrm{p}^{\mathrm{c}}\right)>0,(\mathrm{~A} 1)$ and (A4) together imply that $\mathrm{q}\left(\mathrm{p}^{\mathrm{c}}\right)+\left(\mathrm{p}^{\mathrm{c}}-\mathrm{c}\right) \cdot\left(\partial \mathrm{q}\left(\mathrm{p}^{\mathrm{c}}\right) / \partial \mathrm{p}^{\mathrm{c}}\right)<0$ for $\mathrm{p}^{\mathrm{c}} \geq$ $\mathrm{p}_{0}^{\mathrm{f}}$ with $\mathrm{q}\left(\mathrm{p}^{\mathrm{c}}\right)>0$, which in turn implies $\left(\mathrm{p}_{0}-\mathrm{c}\right) \cdot \mathrm{q}\left(\mathrm{p}_{0}\right)<\left(\mathrm{p}_{0}^{\prime}-\mathrm{c}\right) \cdot \mathrm{q}\left(\mathrm{p}_{0}^{\prime}\right) . \mathrm{V}\left(\mathrm{p}_{0}^{\prime}\right)=\mathrm{V}\left(\mathrm{p}_{0}\right)$ because $T_{1}=1$ for both $p_{0}^{\prime}$ and $p_{0}$. Now, consider that the firm chooses $p_{1}>p_{0}^{f}$ with $T_{1} \leq p_{0}^{f} / c$. This cannot be a part of optimal pricing path since setting $\mathrm{p}_{1}{ }_{1}=\mathrm{p}_{0}^{\mathrm{f}}$ will strictly raise the discounted payoff, $\left(\mathrm{p}_{1}^{\prime}-\mathrm{c}\right) \cdot \mathrm{q}\left(\mathrm{p}_{1}{ }^{\prime} \cdot \mathrm{T}_{1}\right)+\mathrm{V}\left(\mathrm{p}_{1}{ }^{\prime}\right)>\left(\mathrm{p}_{1}-\mathrm{c}\right) \cdot \mathrm{q}\left(\mathrm{p}_{1} \cdot \mathrm{T}_{1}\right)+\mathrm{V}\left(\mathrm{p}_{1}\right)$. (A4) implies that $\mathrm{q}\left(\mathrm{p} \cdot \mathrm{T}_{1}\right)$ $+(p-c) \cdot T_{1} \cdot\left(\partial q\left(p \cdot T_{1}\right) / \partial p^{c}\right)$ is a decreasing function in $T_{1}$ with $q\left(p^{c}\right)+\left(p^{c}-c\right) \cdot\left(\partial q\left(p^{c}\right) / \partial p^{c}\right)<0$ for $p^{c}$ $\geq \mathrm{p}_{0}^{\mathrm{f}}$ from $(\mathrm{A} 1)$. Thus, $\mathrm{q}\left(\mathrm{pT}_{1}\right)+(\mathrm{p}-\mathrm{c}) \cdot \mathrm{T}_{1} \cdot\left(\partial \mathrm{q}\left(\mathrm{p} \cdot \mathrm{T}_{1}\right) / \partial \mathrm{p}^{\mathrm{c}}\right)<0$ for $\mathrm{p} \geq \mathrm{p}_{0}^{\mathrm{f}}$, implying that $\left(\mathrm{p}_{1}-\mathrm{c}\right)$ $\cdot \mathrm{q}\left(\mathrm{p}_{1} \cdot \mathrm{T}_{1}\right)<\left(\mathrm{p}_{1}^{\prime}-\mathrm{c}\right) \cdot \mathrm{q}\left(\mathrm{p}_{1}{ }^{\prime} \cdot \mathrm{T}_{1}\right) \cdot \mathrm{V}\left(\mathrm{p}_{1}{ }^{\prime}\right)=\mathrm{V}\left(\mathrm{p}_{1}\right)$ because $\mathrm{T}_{2}=1$ for both $\mathrm{p}_{1}^{\prime}$ and $\mathrm{p}_{1}$. For the next period on, we can apply the same logic that we use for period 1.

\section{Proof for Lemma 3}

First, note that $\mathrm{p}^{\prime}$ in $\mathrm{G}\left(\mathrm{p}^{\prime}\right)$ defines the current period $\mathrm{AD}$ duty by $\mathrm{T}^{\prime}=\mathrm{p}_{0}^{\mathrm{f}} / \mathrm{p}^{\prime}$, since we can focus on $\mathrm{p}^{\prime} \in\left(\mathrm{c}, \mathrm{p}_{0}^{\mathrm{f}}\right]$ due to Lemma 2 . By definition of $1\left(\mathrm{p}^{\prime}\right)$, 


$$
\left(1\left(p^{\prime}\right)-c\right) \cdot q\left(1\left(p^{\prime}\right) \cdot T^{\prime}\right)+\delta V\left(1\left(p^{\prime}\right)\right) \geq(p-c) \cdot q\left(p \cdot T^{\prime}\right)+\delta V(p) \text { for all } p \in\left(c, p_{0}^{f}\right]
$$

Consider $\mathrm{p}^{\prime \prime}<\mathrm{p}^{\prime}$, thus $\mathrm{T}^{\prime \prime}>\mathrm{T}^{\prime}$. Then, there exists $\alpha \geq 0$ such that $\left(1\left(\mathrm{p}^{\prime}\right)-\mathrm{c}\right) \cdot \mathrm{q}\left(1\left(\mathrm{p}^{\prime}\right) \cdot \mathrm{T}^{\prime \prime}\right)+\delta \mathrm{V}\left(1\left(\mathrm{p}^{\prime}\right)\right)$ $+\alpha=\left(1\left(\mathrm{p}^{\prime}\right)-\mathrm{c}\right) \cdot \mathrm{q}\left(1\left(\mathrm{p}^{\prime}\right) \cdot \mathrm{T}^{\prime}\right)+\delta \mathrm{V}\left(1\left(\mathrm{p}^{\prime}\right)\right)$ because $\partial \mathrm{q}\left(\mathrm{p}^{\mathrm{c}}\right) / \partial \mathrm{p}^{\mathrm{c}} \leq 0$. We can show that

$$
(p-c) \cdot q\left(p \cdot T^{\prime}\right)+\delta V(p)>(p-c) \cdot q\left(p \cdot T^{\prime \prime}\right)+\delta V(p)+\alpha \text { for all } p \in\left(1\left(p^{\prime}\right), p_{0}^{f}\right]
$$

Define $\mathrm{A}(\mathrm{p})=\left[(\mathrm{p}-\mathrm{c}) \cdot \mathrm{q}\left(\mathrm{p} \cdot \mathrm{T}^{\prime}\right)+\delta \cdot \mathrm{V}(\mathrm{p})\right]-\left[(\mathrm{p}-\mathrm{c}) \cdot \mathrm{q}\left(\mathrm{p} \cdot \mathrm{T}^{\prime \prime}\right)+\delta \mathrm{V}(\mathrm{p})+\alpha\right]$. By definition of $\alpha$, $\mathrm{A}(1(\mathrm{p}))=0$ and $\partial \mathrm{A}(\mathrm{p}) / \partial \mathrm{p}=\left[\mathrm{q}\left(\mathrm{p} \cdot \mathrm{T}^{\prime}\right)-\mathrm{q}\left(\mathrm{p} \cdot \mathrm{T}^{\prime \prime}\right)\right]+(\mathrm{p}-\mathrm{c}) \cdot\left[\mathrm{T}^{\prime} \cdot\left(\partial \mathrm{q}\left(\mathrm{p} \mathrm{T}^{\prime}\right) / \partial \mathrm{p}^{\mathrm{c}}\right)-\mathrm{T}^{\prime \prime} \cdot\left(\partial \mathrm{q}\left(\mathrm{p} \mathrm{T}^{\prime \prime}\right) / \partial \mathrm{p}^{\mathrm{c}}\right)\right]>0$ for $\mathrm{p} \in\left[1\left(\mathrm{p}^{\prime}\right), \mathrm{p}_{0}^{\mathrm{f}}\right] . \partial \mathrm{A}(\mathrm{p}) / \partial \mathrm{p}>0$ because $\mathrm{q}(\mathrm{p} \cdot \mathrm{T})+(\mathrm{p}-\mathrm{c}) \cdot \mathrm{T} \cdot\left(\partial \mathrm{q}(\mathrm{p} \cdot \mathrm{T}) / \partial \mathrm{p}^{\mathrm{c}}\right)$ is strictly decreasing in T by (A4): $\left(\partial \mathrm{q}\left(\mathrm{p}^{\mathrm{c}}\right) / \partial \mathrm{p}^{\mathrm{c}}\right) \cdot \mathrm{p}+(\mathrm{p}-\mathrm{c}) \cdot\left[\left(\partial \mathrm{q}\left(\mathrm{p}^{\mathrm{c}}\right) / \partial \mathrm{p}^{\mathrm{c}}\right)+\left(\partial^{2} \mathrm{q}\left(\mathrm{p}^{\mathrm{c}}\right) / \partial \mathrm{p}^{\mathrm{c} 2}\right) \cdot \mathrm{p}^{\mathrm{c}}\right]<0$. From (a1), (a2), and $\left(1\left(p^{\prime}\right)-c\right) \cdot q\left(1\left(p^{\prime}\right) \cdot T^{\prime \prime}\right)+\delta \mathrm{V}\left(1\left(p^{\prime}\right)\right)+\alpha=\left(1\left(p^{\prime}\right)-c\right) \cdot q\left(1\left(p^{\prime}\right) \cdot T^{\prime}\right)+\delta V\left(1\left(p^{\prime}\right)\right)$, we have $\left(1\left(p^{\prime}\right)-c\right)$. $\mathrm{q}\left(1\left(\mathrm{p}^{\prime}\right) \cdot \mathrm{T}^{\prime \prime}\right)+\delta \mathrm{V}\left(1\left(\mathrm{p}^{\prime}\right)\right)>(\mathrm{p}-\mathrm{c}) \mathrm{q}\left(\mathrm{p} \mathrm{T}^{\prime \prime}\right)+\delta \mathrm{V}(\mathrm{p})$ for all $\mathrm{p} \in\left(1\left(\mathrm{p}^{\prime}\right), \mathrm{p}_{0}^{\mathrm{f}}\right]$. Thus, $\mathrm{p} \notin \mathrm{G}\left(\mathrm{p}^{\prime \prime}\right)$ for $\mathrm{p} \in$ $\left(1\left(\mathrm{p}^{\prime}\right), \mathrm{p}_{0}^{\mathrm{f}}\right]$, implying $\mathrm{h}\left(\mathrm{p}^{\prime \prime}\right) \leq 1\left(\mathrm{p}^{\prime}\right)$ for $\mathrm{p}^{\prime \prime}<\mathrm{p}^{\prime}$.

\section{Proof for Proposition 1}

First, we can easily show that there exists a critical level of $\delta$, denoted by $\delta^{\mathrm{c}}$, such that the foreign firm will dump in the initial period, $\mathrm{p}_{0}<\mathrm{p}_{0}^{\mathrm{f}}$ if $\delta<\delta^{\mathrm{c}}$ and will not dump, $\mathrm{p}_{0}=\mathrm{p}_{0}^{\mathrm{f}}$ if $\delta>\delta^{\mathrm{c}}$. The foreign firm will not dump in the initial period if $\pi\left(\mathrm{p}_{0}^{\mathrm{f}} ; \mathrm{T}_{0}=1\right)+\delta \mathrm{V}\left(\mathrm{p}_{0}^{\mathrm{f}}\right)>\pi\left(\mathrm{p} ; \mathrm{T}_{0}=1\right)+$ $\delta \mathrm{V}(\mathrm{p})$, or equivalently $\pi\left(\mathrm{p} ; \mathrm{T}_{0}=1\right)-\pi\left(\mathrm{p}_{0}^{\mathrm{f}} ; \mathrm{T}_{0}=1\right)<\delta\left[\mathrm{V}\left(\mathrm{p}_{0}^{\mathrm{f}}\right)-\mathrm{V}(\mathrm{p})\right]$ for all $\mathrm{p} \in\left(\mathrm{c}, \mathrm{p}_{0}^{\mathrm{f}}\right)$. Define a set $\Delta \equiv\left\{\delta \in[0,1) \mid \operatorname{Max}_{\mathrm{p} \in\left[\mathrm{c}, \mathrm{p}_{0}^{\mathrm{f}}\right]}\left\{\left[\pi\left(\mathrm{p} ; \mathrm{T}_{0}\right)-\pi\left(\mathrm{p}_{0}^{\mathrm{f}} ; \mathrm{T}_{0}\right)\right]-\delta\left[\mathrm{V}\left(\mathrm{p}_{0}^{\mathrm{f}}\right)-\mathrm{V}(\mathrm{p})\right]\right\} \geq 0\right\}$. Then, $\Delta \notin \varnothing$ because there exists $p^{\prime} \in\left(c, p_{0}^{f}\right)$ such that $\pi\left(p^{\prime} ; T_{0}=1\right)-\pi\left(p_{0}^{f} ; T_{0}=1\right)>0$ from (A1) and (A4). Now, define $\delta^{\mathrm{c}} \equiv \operatorname{Sup}(\Delta)$, then the foreign firm will set $\mathrm{p}_{0}<\mathrm{p}_{0}^{\mathrm{f}}$ if $\delta<\delta^{\mathrm{c}}$. If $\delta^{\mathrm{c}}=1$, then the foreign firm will dump for all $\delta \in(0,1)$. If $\delta^{\mathrm{c}}<1$, the foreign will not dump in the initial period if $\delta>\delta^{\mathrm{c}}$.

To prove (ii), we can use the same argument as in Lemma 3. With $\delta<\delta^{\mathrm{c}}$, the foreign firm will set its initial optimal price, $\mathrm{p}_{0}<\mathrm{p}_{0}^{\mathrm{f}}$, having

$$
\left(\mathrm{p}_{0}-\mathrm{c}\right) \cdot \mathrm{q}\left(\mathrm{p}_{0} \cdot \mathrm{T}_{0}\right)+\delta \mathrm{V}\left(\mathrm{p}_{0}\right) \geq(\mathrm{p}-\mathrm{c}) \cdot \mathrm{q}\left(\mathrm{p} \cdot \mathrm{T}_{0}\right)+\delta \mathrm{V}(\mathrm{p}) \text { for all } \mathrm{p} \in\left(\mathrm{c}, \mathrm{p}_{0}^{\mathrm{f}}\right]
$$

where $T_{0}=1$. In the next period, the firm will try to choose $\mathrm{p}_{1}$ to maximize its discounted profit given that $\mathrm{T}_{1}=\mathrm{p}_{0}^{\mathrm{f}} / \mathrm{p}_{0}>1$. Let's consider $\mathrm{p}_{1}=\mathrm{p}_{0}$ as such a choice, then there exists $\alpha \geq 0$ such that $\left(\mathrm{p}_{0}-\mathrm{c}\right) \cdot \mathrm{q}\left(\mathrm{p}_{0} \cdot \mathrm{T}_{1}\right)+\delta \mathrm{V}\left(\mathrm{p}_{0}\right)+\alpha=\left(\mathrm{p}_{0}-\mathrm{c}\right) \cdot \mathrm{q}\left(\mathrm{p}_{0} \cdot \mathrm{T}_{0}\right)+\delta \mathrm{V}\left(\mathrm{p}_{0}\right)$ because $\partial \mathrm{q}\left(\mathrm{p}^{\mathrm{c}}\right) / \partial \mathrm{p}^{\mathrm{c}} \leq 0$ and $\mathrm{T}_{1}>\mathrm{T}_{0}$. We can show that

$$
(p-c) q\left(p T_{0}\right)+\delta V(p)>(p-c) q\left(p T_{1}\right)+\delta V(p)+\alpha \text { for all } p \in\left(p_{0}, p_{0}^{f}\right]
$$

Define $\mathrm{A}(\mathrm{p})=\left[(\mathrm{p}-\mathrm{c}) \mathrm{q}\left(\mathrm{pT}_{0}\right)+\delta \mathrm{V}(\mathrm{p})\right]-\left[(\mathrm{p}-\mathrm{c}) \mathrm{q}\left(\mathrm{pT}_{1}\right)+\delta \mathrm{V}(\mathrm{p})+\alpha\right]$. By definition of $\alpha, \mathrm{A}\left(\mathrm{p}_{0}\right)=$ 0 and $\partial \mathrm{A}(\mathrm{p}) / \partial \mathrm{p}=\left[\mathrm{q}\left(\mathrm{pT}_{0}\right)-\mathrm{q}\left(\mathrm{pT}_{1}\right)\right]+(\mathrm{p}-\mathrm{c})\left[\mathrm{T}_{0}\left(\partial \mathrm{q}\left(\mathrm{pT}_{0}\right) / \partial \mathrm{p}^{\mathrm{c}}\right)+\mathrm{T}_{1}\left(\partial \mathrm{q}\left(\mathrm{pT}_{1}\right) / \partial \mathrm{p}^{\mathrm{c}}\right)\right]>0$ for $\mathrm{p} \in\left[\mathrm{p}_{0}\right.$ 
$\left.\mathrm{p}_{0}^{\mathrm{f}}\right]$ by the same reason as in Lemma 3. From (a3), (a4), and $\left(\mathrm{p}_{0}-\mathrm{c}\right) \cdot \mathrm{q}\left(\mathrm{p}_{0} \cdot \mathrm{T}_{1}\right)+\delta \mathrm{V}\left(\mathrm{p}_{0}\right)+\alpha=$ $\left(\mathrm{p}_{0}-\mathrm{c}\right) \cdot \mathrm{q}\left(\mathrm{p}_{0} \cdot \mathrm{T}_{0}\right)+\delta \mathrm{V}\left(\mathrm{p}_{0}\right)$, we have $\left(\mathrm{p}_{0}-\mathrm{c}\right) \cdot \mathrm{q}\left(\mathrm{p}_{0} \cdot \mathrm{T}_{1}\right)+\delta \mathrm{V}\left(\mathrm{p}_{0}\right)>(\mathrm{p}-\mathrm{c}) \mathrm{q}\left(\mathrm{pT}_{1}\right)+\delta \mathrm{V}(\mathrm{p})$ for all $\mathrm{p} \in\left(\mathrm{p}_{0}, \mathrm{p}_{0}^{\mathrm{f}}\right]$. This implies $\mathrm{p}_{1} \notin\left(\mathrm{p}_{0}, \mathrm{p}_{0}^{\mathrm{f}}\right]$, thus $\mathrm{p}_{1} \leq \mathrm{p}_{0}$. If $\mathrm{p}_{1}<\mathrm{p}_{0}$, then we can repeat the same argument as above to show that $\mathrm{p}_{2} \leq \mathrm{p}_{1}$ by replacing $\mathrm{T}_{0}$ and $\mathrm{T}_{1}\left(>\mathrm{T}_{0}\right)$ with $\mathrm{T}_{1}$ and $\mathrm{T}_{2}\left(>\mathrm{T}_{1}\right)$. If $\mathrm{p}_{1}=\mathrm{p}_{0}$, then we can use the exactly same argument as above to show that $\mathrm{p}_{2} \leq \mathrm{p}_{1}=\mathrm{p}_{0}$.

\section{Proof for Proposition 2}

(i) To prove $\mathrm{p}_{0}^{\mathrm{E}}$ is increasing in $\operatorname{Pr}(\mathrm{ADD})$, we use a similar argument as in Lemma 3. Let's assume that the foreign firm sets its initial optimal price, $\mathrm{p}_{0}^{\mathrm{E}}$ for a given $\operatorname{Pr}(\mathrm{ADD})$, having

$$
\begin{aligned}
& \left(\mathrm{p}_{0}^{\mathrm{E}}-\mathrm{c}\right) \cdot \mathrm{q}\left(\mathrm{p}_{0}^{\mathrm{E}}\right)+\delta \cdot\left[\operatorname{Pr}(\mathrm{ADD}) \cdot \mathrm{V}\left(\mathrm{p}_{0}^{\mathrm{E}}\right)+\operatorname{Pr}(\mathrm{TER}) \cdot \mathrm{V}^{\mathrm{T}}\left(\mathrm{p}_{0}^{\mathrm{E}}\right)\right] \geq \\
& (\mathrm{p}-\mathrm{c}) \cdot \mathrm{q}(\mathrm{p})+\delta \cdot\left[\operatorname{Pr}(\mathrm{ADD}) \cdot \mathrm{V}(\mathrm{p})+\operatorname{Pr}(\mathrm{TER}) \cdot \mathrm{V}^{\mathrm{T}}(\mathrm{p})\right] \text { for all } \mathrm{p} \in\left(\mathrm{c}, \mathrm{p}_{0}^{\mathrm{f}}\right] .
\end{aligned}
$$

Now consider $\operatorname{Pr}^{\prime}(A D D)>\operatorname{Pr}(A D D)$, and the foreign firm tries to set its initial optimal price $p_{0}^{E^{\prime}}$ for the given $\operatorname{Pr}^{\prime}(A D D)$. There exists $\alpha>0$ such that $\left(\mathrm{p}_{0}^{\mathrm{E}}-\mathrm{c}\right) \cdot \mathrm{q}\left(\mathrm{p}_{0}^{\mathrm{E}}\right)+\delta \cdot \operatorname{Pr}^{\prime}(\mathrm{ADD}) \cdot \mathrm{V}\left(\mathrm{p}_{0}^{\mathrm{E}}\right)-\alpha=$ $\left(\mathrm{p}_{0}^{\mathrm{E}}-\mathrm{c}\right) \cdot \mathrm{q}\left(\mathrm{p}_{0}^{\mathrm{E}}\right)+\delta \cdot \operatorname{Pr}(\mathrm{ADD}) \cdot \mathrm{V}\left(\mathrm{p}_{0}^{\mathrm{E}}\right)$ because $\operatorname{Pr}^{\prime}(\mathrm{ADD})>\operatorname{Pr}(\mathrm{ADD})$. We can show that

$$
\begin{aligned}
& (p-c) \cdot q(p)+\delta \cdot\left[\operatorname{Pr}(A D D) \cdot V(p)+\operatorname{Pr}(T E R) \cdot V^{T}(p)\right]> \\
& (p-c) \cdot q(p)+\delta \cdot\left[\operatorname{Pr}^{\prime}(A D D) \cdot V(p)+\operatorname{Pr}(T E R) \cdot V^{T}(p)\right]-\alpha, \text { for all } p \in\left(c, p_{0}^{E}\right)
\end{aligned}
$$

Define $\mathrm{A}(\mathrm{p})=[(\mathrm{p}-\mathrm{c}) \cdot \mathrm{q}(\mathrm{p})+\delta \cdot \operatorname{Pr}(\mathrm{ADD}) \cdot \mathrm{V}(\mathrm{p})]-\left[(\mathrm{p}-\mathrm{c}) \cdot \mathrm{q}(\mathrm{p})+\delta \cdot \operatorname{Pr}^{\prime}(\mathrm{ADD}) \cdot \mathrm{V}(\mathrm{p})-\alpha\right] . \quad B y$ definition of $\alpha, \mathrm{A}\left(\mathrm{p}_{0}^{\mathrm{E}}\right)=0$ and $\mathrm{A}(\mathrm{p})=\left[\operatorname{Pr}(\mathrm{ADD})-\operatorname{Pr}^{\prime}(\mathrm{ADD})\right] \cdot \mathrm{V}(\mathrm{p})+\alpha>0$ for $\mathrm{p} \in\left(\mathrm{c}, \mathrm{p}_{0}^{\mathrm{E}}\right)$ because $\mathrm{V}(\mathrm{p})$ is strictly increasing in $\mathrm{p} \in\left(\mathrm{c}, \mathrm{p}_{0}^{\mathrm{f}}\right]$. From (a5), (a6), and $\left(\mathrm{p}_{0}^{\mathrm{E}}-\mathrm{c}\right) \cdot \mathrm{q}\left(\mathrm{p}_{0}^{\mathrm{E}}\right)+$ $\delta \cdot \operatorname{Pr}^{\prime}(A D D) \cdot V\left(p_{0}^{E}\right)-\alpha=\left(p_{0}^{E}-c\right) \cdot q\left(p_{0}^{E}\right)+\delta \cdot \operatorname{Pr}(A D D) \cdot V\left(p_{0}^{E}\right)$, we have $\left(p_{0}^{E}-c\right) \cdot q\left(p_{0}^{E}\right)+$ $\delta \cdot \operatorname{Pr}^{\prime}(A D D) \cdot V\left(p_{0}^{E}\right)>(p-c) \cdot q(p)+\delta \cdot \operatorname{Pr}^{\prime}(A D D) \cdot V(p)$ for all $\mathrm{p} \in\left(c, p_{0}^{E}\right)$. This implies $p_{0}^{E_{1}} \geq p_{0}^{E}$ for all $\operatorname{Pr}^{\prime}(\mathrm{ADD})>\operatorname{Pr}(\mathrm{ADD})$.

(ii) We can use the same argument as in the proof for Proposition 2 (i), except using that there exists $\alpha>0$ such that $\left(\mathrm{p}_{0}^{\mathrm{E}}-\mathrm{c}\right) \cdot \mathrm{q}\left(\mathrm{p}_{0}^{\mathrm{E}}\right)+\delta \cdot \operatorname{Pr}($ TER $) \cdot \mathrm{V}\left(\mathrm{p}_{0}^{\mathrm{E}}\right)-\alpha=\left(\mathrm{p}_{0}^{\mathrm{E}}-\mathrm{c}\right) \cdot \mathrm{q}\left(\mathrm{p}_{0}^{\mathrm{E}}\right)+$ $\delta \cdot \operatorname{Pr}(\mathrm{TER}) \cdot \mathrm{V}\left(\mathrm{p}_{0}^{\mathrm{E}}\right)$ and

$$
\begin{aligned}
& (\mathrm{p}-\mathrm{c}) \cdot \mathrm{q}(\mathrm{p})+\delta \cdot\left[\operatorname{Pr}(\mathrm{ADD}) \cdot \mathrm{V}(\mathrm{p})+\operatorname{Pr}(\mathrm{TER}) \cdot \mathrm{V}^{\mathrm{T}}(\mathrm{p})\right]> \\
& (\mathrm{p}-\mathrm{c}) \cdot \mathrm{q}(\mathrm{p})+\delta \cdot\left[\operatorname{Pr}(\mathrm{ADD}) \cdot \mathrm{V}(\mathrm{p})+\operatorname{Pr}^{\prime}(\mathrm{TER}) \cdot \mathrm{V}^{\mathrm{T}}(\mathrm{p})\right]-\alpha
\end{aligned}
$$

for all $\mathrm{p} \in\left(\mathrm{p}_{0}^{\mathrm{E}}, \mathrm{p}_{0}^{\mathrm{f}}\right]$ if $\mathrm{V}^{\mathrm{T}}(\mathrm{p})$ is strictly decreasing in $\mathrm{p}$, or for all $\mathrm{p} \in\left(\mathrm{c}, \mathrm{p}_{0}^{\mathrm{E}}\right)$ if $\mathrm{V}^{\mathrm{T}}(\mathrm{p})$ is strictly increasing in $\mathrm{p}$. 


\section{Proof for Corollary 1.}

(i) $\quad$ Define a set $\mathrm{A} \equiv\left\{\operatorname{Pr}(\mathrm{ADD}) \in[0,1] \mid \operatorname{Aug} \max _{\mathrm{f}}[(\mathrm{p}-\mathrm{c}) \mathrm{q}(\mathrm{p})+\operatorname{Pr}(\mathrm{ADD}) \cdot \delta \cdot \mathrm{V}(\mathrm{p})]<\mathrm{p}_{0}^{\mathrm{f}}\right\}$. $\mathrm{p} \in\left[\mathrm{c}, \mathrm{p}_{0}^{\mathrm{f}}\right]$

Then, $A \notin \varnothing$ because $\underset{\mathrm{p} \in\left[\mathrm{c}, \mathrm{p}^{\mathrm{f}}\right]}{\operatorname{Arg} \max }[(\mathrm{p}-\mathrm{c}) \mathrm{q}(\mathrm{p})] \equiv \mathrm{p}^{*}<\mathrm{p}_{0}^{\mathrm{f}}$ from (A1). Now, define $\operatorname{Pr}^{\mathrm{c}}(\mathrm{ADD}) \equiv$ $\mathrm{p} \in\left[\mathrm{c}, \mathrm{p}_{0}^{\mathrm{f}}\right]$

Sup(A), then the foreign firm will set $\mathrm{p}_{0}^{\mathrm{E}}<\mathrm{p}_{0}^{\mathrm{f}}$ if $\operatorname{Pr}(\mathrm{ADD})<\operatorname{Pr}^{\mathrm{C}}(\mathrm{ADD})$ because $\mathrm{p}_{0}^{\mathrm{E}}$ is increasing in $\operatorname{Pr}(\mathrm{ADD})$ from Proposition 2. If an ADD case occurs with $\mathrm{T}_{\mathrm{i}+1}^{\mathrm{di}}=\mathrm{p}_{0}^{\mathrm{f}} / \mathrm{p}_{0}^{\mathrm{E}}>1$ at period $\mathrm{i}$, then the following pricing path $\left\{\mathrm{p}_{0}^{\mathrm{di}}, \mathrm{p}_{1}^{\mathrm{di}}, \mathrm{p}_{2}^{\mathrm{di}}, \ldots\right\}$ under the administrative review will be determined by $G\left(p_{0}^{E}\right)$; note that the administrative review is enforced with certainty. Because $p^{S}$ is the unique stationary equilibrium under certain enforcement and $\mathrm{G}(\mathrm{p})$ is a non-decreasing upperhemi continuous correspondence, $\mathrm{p}_{\mathrm{j}}^{\mathrm{di}}$ with $\mathrm{j} \geq \mathrm{i}+1$ will increase toward $\mathrm{p}^{\mathrm{S}}=\mathrm{p}_{0}^{\mathrm{f}}$. This in turn implies that $T_{j}^{\text {di }}$ with $j \geq i+1$ will decrease toward 1 .

(ii) For the foreign firm with $\mathrm{p}^{\mathrm{S}}<\mathrm{p}_{0}^{\mathrm{f}}, \underset{\mathrm{p} \in\left[\mathrm{c}, \mathrm{p}_{\mathrm{p}}^{\mathrm{f}}\right]}{\operatorname{Arg} \max }[(\mathrm{p}-\mathrm{c}) \mathrm{q}(\mathrm{p})] \equiv \mathrm{p}^{*}<\mathrm{p}^{\mathrm{S}}$ is a necessary condition for the existence of $\operatorname{Pr}^{\mathrm{c}}(\mathrm{ADD}) \in[0,1]$ such that the foreign firm sets $\mathrm{p}_{0}^{\mathrm{E}}<\mathrm{p}^{\mathrm{S}}$ for $\operatorname{Pr}(\mathrm{ADD})<$ $\operatorname{Pr}^{\mathrm{c}}(\mathrm{ADD})$. Note that $\mathrm{p}_{0}^{\mathrm{E}}=\mathrm{p}^{*}$ when $\operatorname{Pr}(\mathrm{ADD})=0$ (and $\operatorname{Pr}(\mathrm{TER})=0$ ). Because $\mathrm{p}_{0}^{\mathrm{E}}$ is increasing in $\operatorname{Pr}(A D D)$ as shown in Proposition $2, \mathrm{p}^{*} \geq \mathrm{p}^{\mathrm{s}}$ will imply $\mathrm{p}_{0}^{\mathrm{E}} \geq \mathrm{p}^{\mathrm{s}}$ for all $\operatorname{Pr}(\mathrm{ADD}) \in[0,1]$. Define a set $\Omega \equiv\left\{\operatorname{Pr}(\right.$ ADD $\left.) \in[0,1] \mid \operatorname{Aug} \max [(p-c) q(p)+\operatorname{Pr}(A D D) \cdot \delta \cdot V(p)]<p^{S}\right\}$. Then, $\Omega \notin$ $\mathrm{p} \in\left[c, \mathrm{p}_{0}^{\mathrm{f}}\right]$

$\varnothing$ because $\operatorname{Arg} \max [(p-c) q(p)] \equiv p^{*}<p^{S}$. Now, define $\operatorname{Pr}^{c}(A D D) \equiv \operatorname{Sup}(\Omega)$, then the foreign $\mathrm{p} \in\left[\mathrm{c}, \mathrm{p}_{0}^{\mathrm{f}}\right]$

firm will set $\mathrm{p}_{0}^{\mathrm{E}}<\mathrm{p}^{\mathrm{S}}$ if $\operatorname{Pr}(\mathrm{ADD})<\operatorname{Pr}^{\mathrm{c}}(\mathrm{ADD})$ because $\mathrm{p}_{0}^{\mathrm{E}}$ is increasing in $\operatorname{Pr}(\mathrm{ADD})$ from Proposition 2. If an ADD case occurs with $\mathrm{T}_{\mathrm{i}+1}^{\mathrm{di}}=\mathrm{p}_{0}^{\mathrm{f}} / \mathrm{p}_{0}^{\mathrm{E}}>\mathrm{p}_{0}^{\mathrm{f}} / \mathrm{p}^{\mathrm{s}}$ at period $\mathrm{i}$, then the following pricing path $\left\{\mathrm{p}_{0}^{\mathrm{di}}, \mathrm{p}_{1}^{\mathrm{di}}, \mathrm{p}_{2}^{\mathrm{di}}, \ldots\right\}$ under the administrative review will be determined by $\mathrm{G}\left(\mathrm{p}_{0}^{\mathrm{E}}\right)$. Because $\mathrm{p}^{\mathrm{S}}\left(>\mathrm{p}_{0}^{\mathrm{E}}\right)$ is the unique stationary equilibrium under certain enforcement and $\mathrm{G}(\mathrm{p})$ is an increasing upper-hemi continuous correspondence, $p_{j}^{\text {di }}$ with $j \geq i+1$ will increase toward $p^{S}$. This implies that $T_{j}^{d i}$ with $j \geq i+1$ will decrease toward $p_{0}^{\mathrm{f}} / \mathrm{p}^{\mathrm{s}}$.

\section{Proof for Corollary 2.}

First, note that the stationary equilibrium price under the administrative review process, $\mathrm{p}^{\mathrm{S}}$ is not affected by $\operatorname{Pr}(\mathrm{ADD})$ and $\operatorname{Pr}(\mathrm{TER})$. Therefore, $\operatorname{Pr}(\mathrm{ADD})$ and $\operatorname{Pr}(\mathrm{TER})$ affect the increase in the dumping duty through the administrative review process, $\left(p_{0}^{E}-p^{s}\right) / p^{s}$, only through changing the initial price choice, $\mathrm{p}_{0}^{\mathrm{E}}$. Then, Corollary 2 (i), (ii) and (iii) are direct results from corresponding results in Proposition 2. 


\section{References}

Anderson, James E. (1992) "Domino Dumping I: Competitive Exporters," American Economic Review. Vol. 82: 65-83.

Anderson, James E. (1993) "Domino Dumping II: Anti-dumping," Journal of International Economics. Vol. 35: 133-150.

Baldwin, Robert E. (1985) The Political Economy of U.S. Import Policy. Cambridge, MA: The MIT Press.

Blonigen, Bruce A. and Stephen E. Haynes. (forthcoming) "Antidumping Investigations and the Pass-Through of Antidumping Duties and Exchange Rates," American Economic Review.

Blonigen, Bruce A. and Yuka Ohno. (1998) "Endogenous Protection, Foreign Direct Investment and Protection-building Trade," Journal of International Economics, Vol. 46(2): 205-227.

DeVault, James M. (1993). "Economics and the International Trade Commission," Southern Economic Journal, Vol. 60(2): 463-478.

DeVault, James M. (1996) “U.S. Antidumping Administrative Reviews," International Trade Journal. Vol. 10(2): 247-67.

Eichengreen, Barry J., and Hans van der Ven. (1984) "U.S. Antidumping Policies: The Case of Steel," in R.E. Baldwin and A.O. Krueger (Eds.), The Structure and Evolution of Recent U.S. Trade Policy. Chicago: University of Chicago Press for NBER.

Feinberg, Robert M. and Barry T. Hirsch. (1989). "Industry Rent Seeking and the Filing of 'Unfair Trade' Complaints," International Journal of Industrial Organization, Vol. 7(3): 325340.

Finger, J. Michael. (1981). "The Industry-Country Incidence of 'Less than Fair Value' Cases in US Import Trade," Quarterly Review of Economics and Business, Vol. 21(2): 260-279.

Finger, J. Michael, H. Keith Hall, and Douglas R. Nelson. (1982). "The Political Economy of Administered Protection," American Economic Review, Vol. 72(3): 452-466.

Furusawa, Taiji, and Thomas J. Prusa. (1996). "Antidumping Enforcement in a Reciprocal Model of Dumping: Theory and Evidence," Mimeo.

Gallaway, Michael P., Bruce A. Blonigen and Joseph E. Flynn. (1999) "Welfare Costs of the U.S. Antidumping and Countervailing Duty Laws," Journal of International Economics. Vol. 49: 211-244.

Hansen, Wendy L. (1990). "The International Trade Commission and the Politics of Protectionism," American Political Science Review. Vol. 84(1): 21-46. 
Hansen, Wendy L. and Thomas J. Prusa. (1996). "Cumulation and ITC Decision Making: The Sum of the Parts is Greater than the Whole," Economic Inquiry, Vol. 34(4): 746-769.

Hansen, Wendy L. and Thomas J. Prusa. (1997). "The Economics and Politics of Trade Policy: An Empirical Analysis of ITC Decision Making," Review of International Economics, Vol. 5(2): 230-245.

Herander, Mark G. and J. Brad Schwartz. (1984). "An Empirical Test of the Impact of the Threat of US Trade Policy: The Case of Antidumping Duties," Southern Economic Journal, Vol. 51(1): 59-79.

Knetter, Michael M. and Thomas J. Prusa. (2000). "Macroeconomic Factors and Anti-dumping Filings: Evidence from Four Countries,” NBER Working Paper No. 8010.

Krupp, Corinne. (1994). "Antidumping Cases in the US Chemical Industry: A Panel Data Approach," Journal of Industrial Economics. Vol. 42 (3): 299-311.

Krupp, Corinne M., and Patricia S. Pollard. (1996) "Market Responses to Antidumping Laws: Some Evidence from the U.S. Chemical Industry," Canadian Journal of Economics. Vol 29(1): 199-227.

Lichtenberg, Frank and Hong Tan. (1994). "An Industry-Level Analysis of Import Relief Petitions Filed by US Manufacturers, 1958-1985," in Hong Tan and Haruo Shimada (eds.), Troubled Industries in the United States and Japan. New York: St. Martin's Press, 161-88.

Moore, Michael O. (1992). "Rules or Politics? An Empirical Analysis of ITC Anti-dumping Decisions," Economic Inquiry, Vol. 30(3): 449-466.

Pagan, Adrian. (1984). "Econometric Issues in the Analysis of Regressions with Generated Regressors," International Economic Review. Vol. 25( 1): 221-47.

Prusa, Thomas J. (1992) "Why Are So Many Antidumping Petitions Withdrawn?" Journal of International Economics. Vol. 33(1-2): 1-20.

Staiger, Robert W. and Frank A. Wolak. (1994) "Measuring Industry Specific Protection: Antidumping in the United States," Brookings Papers on Economic Activity: Microeconomics, 51-118.

Stokey, Nancy L. and Robert E. Lucas, Jr. with Edward C. Prescott. (1989) "Recursive Methods in Economic Dynamics," Harvard University Press, Cambridge, Massachusetts, and London, England.

Taylor, Christopher T. (2001) "The Economic Effects of Withdrawn Antidumping Investigations: Is There Evidence of Collusive Settlements?” Mimeo.

Zanardi, Maurizio (2000) “Antidumping Law as a Collusive Device," Boston College Working Papers No. 487. 


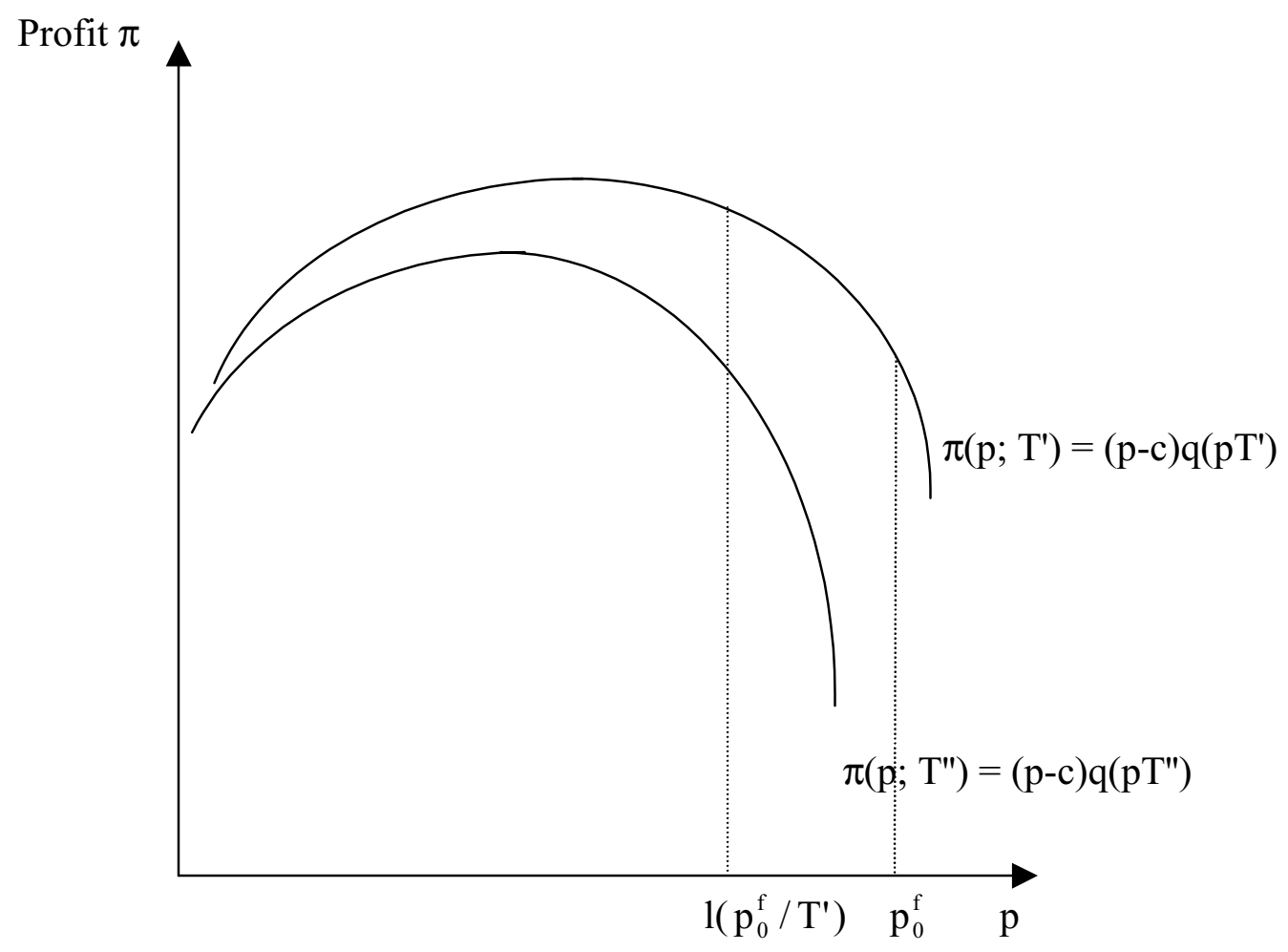

Figure 1a

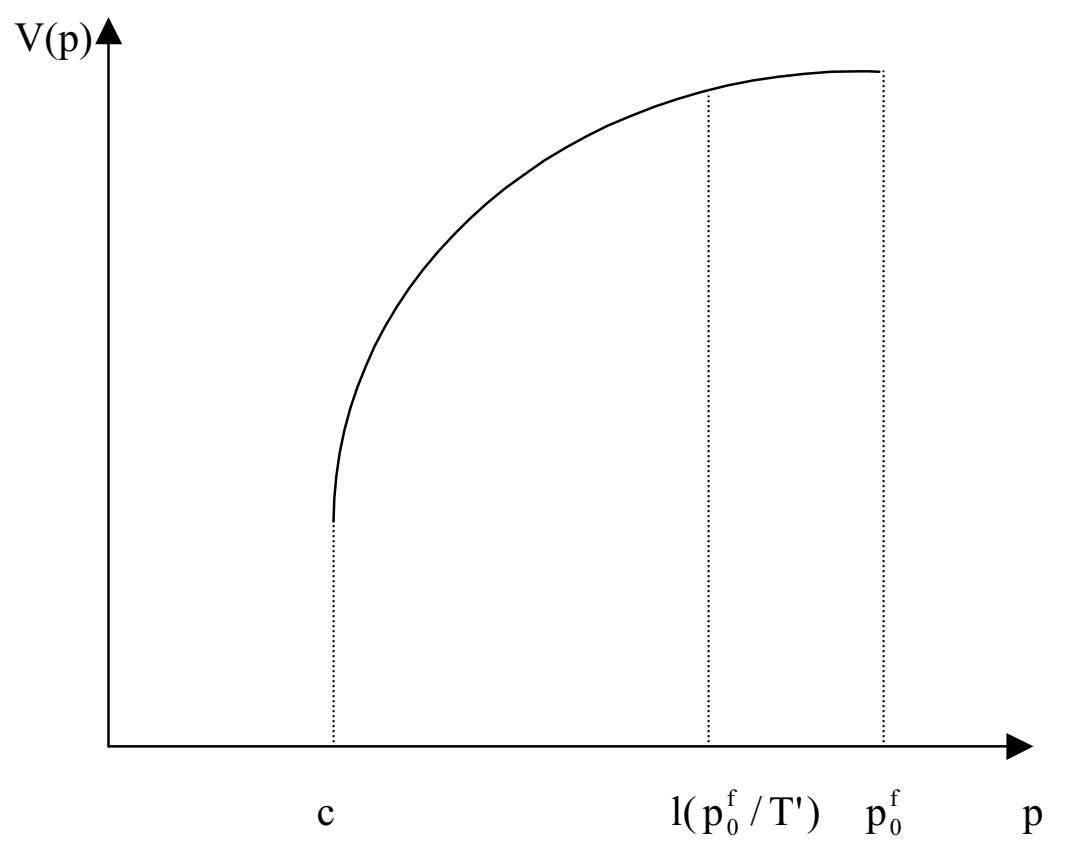

Figure 1b 


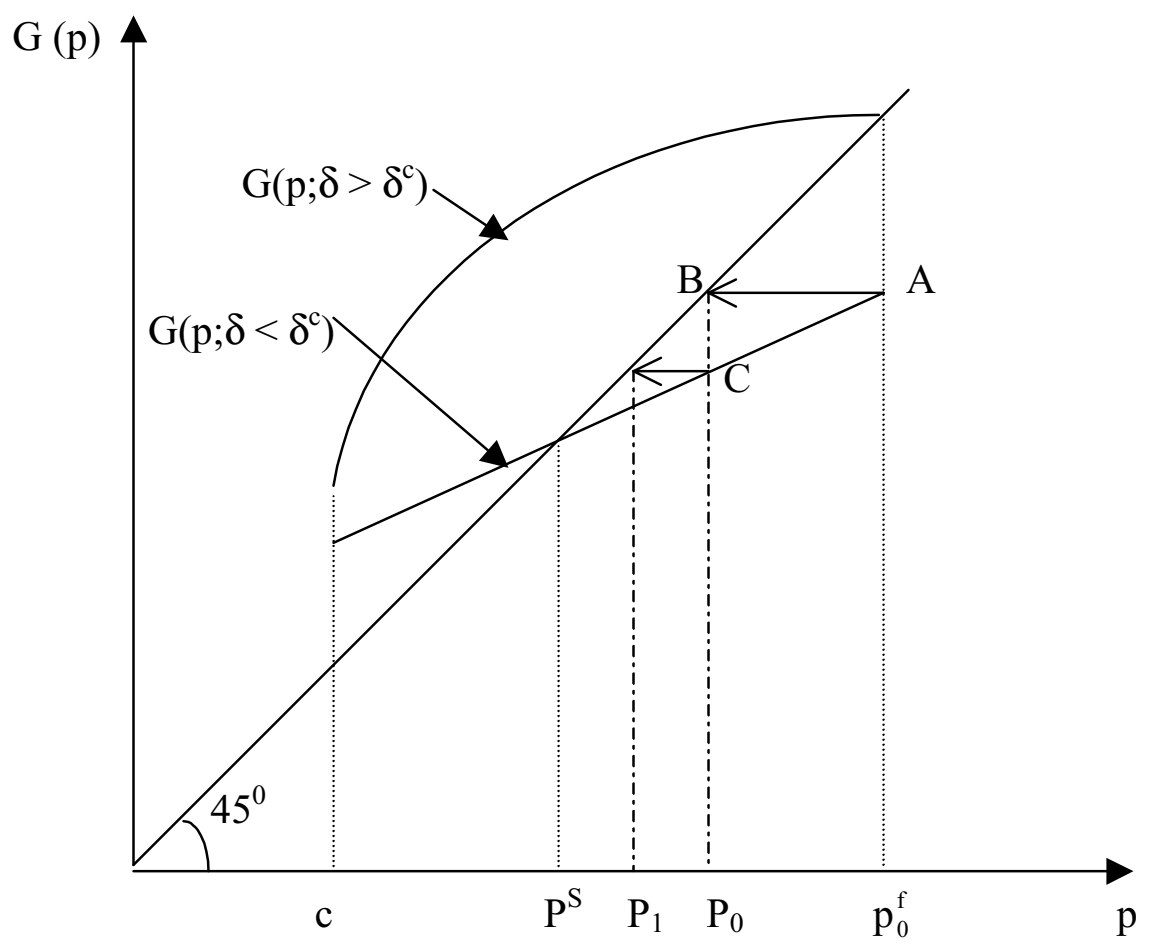

Figure 2a

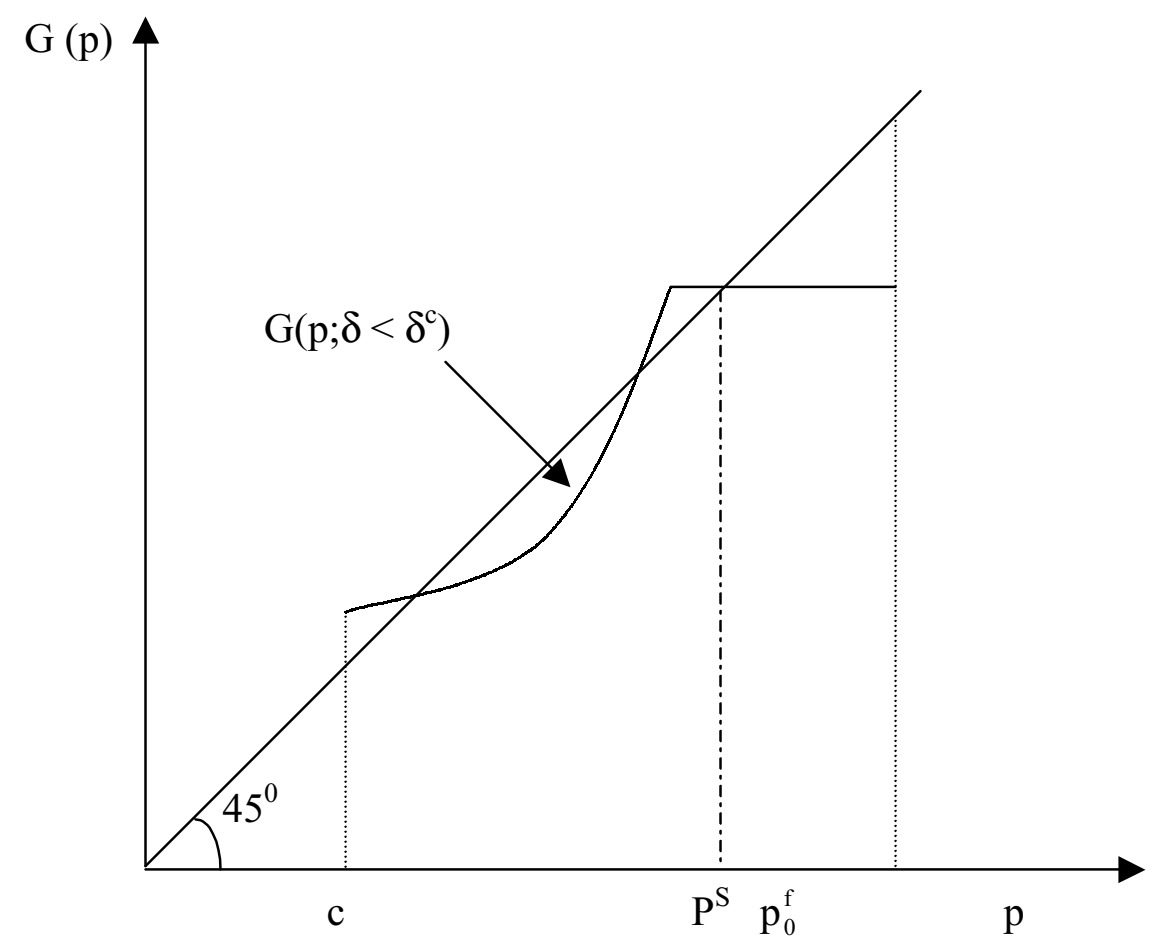

Figure 2b 


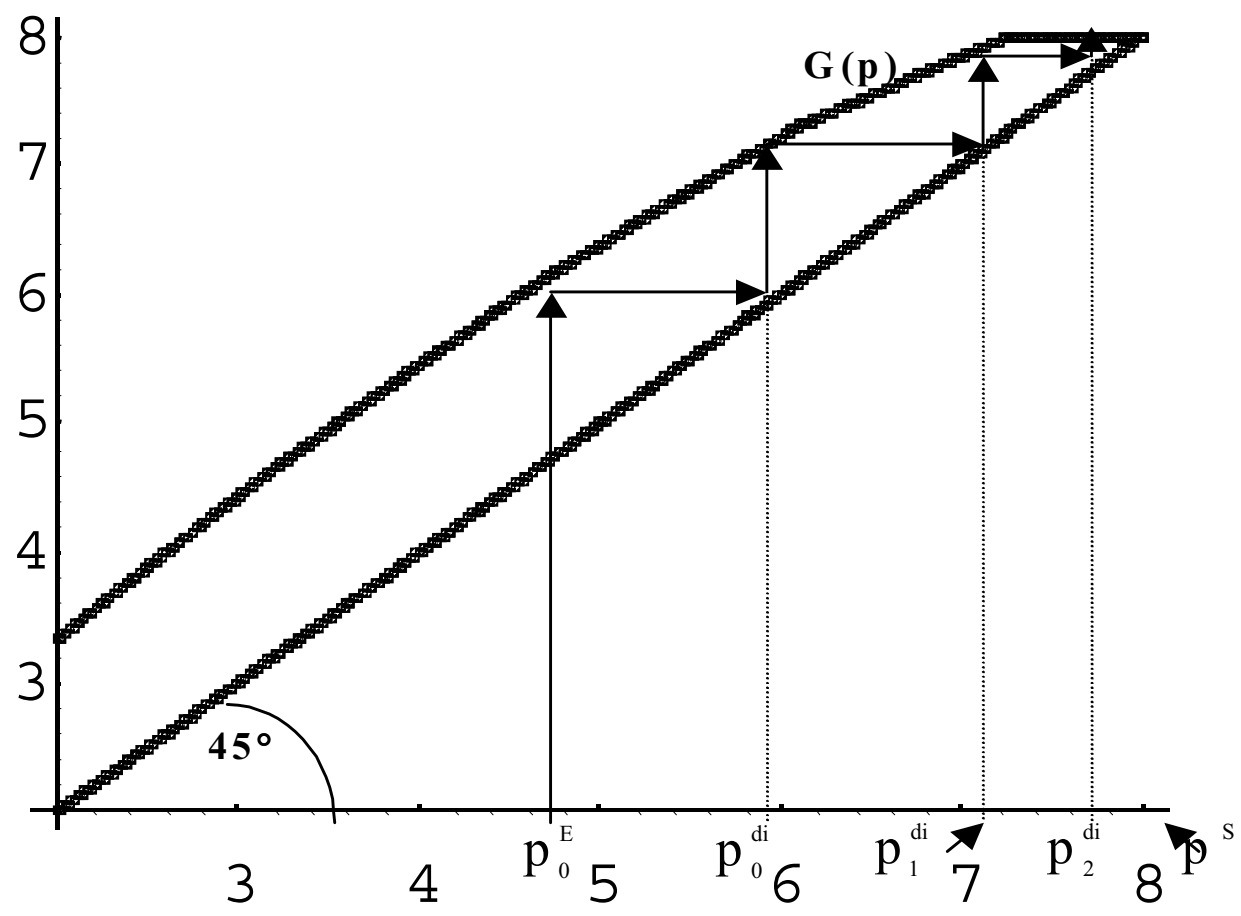

Figure 3a. $(\mathrm{q}(\mathrm{p})=10-\mathrm{p}, \mathrm{c}=2, \mathrm{pf}=8, \delta=0.9)$

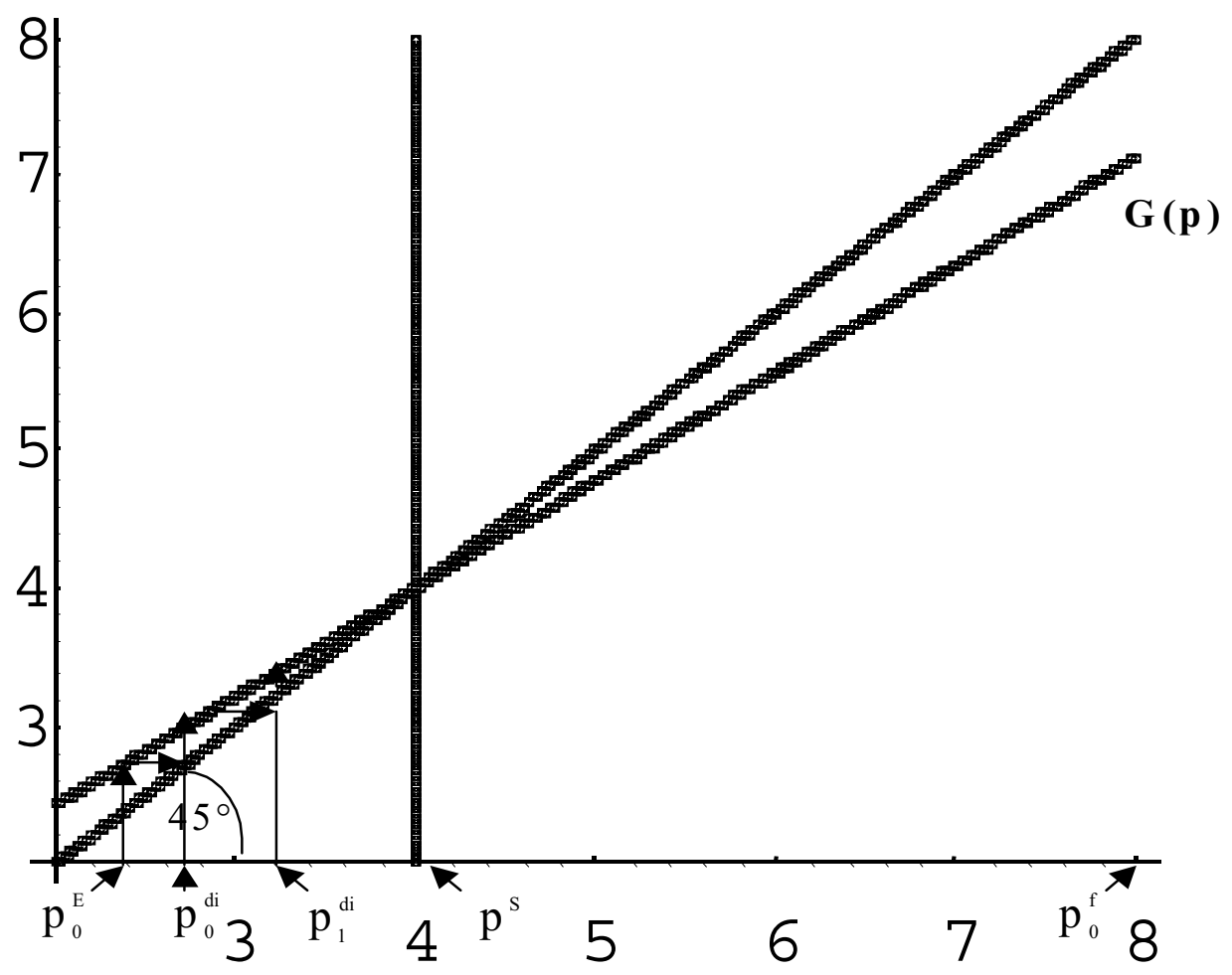

Figure $3 b .(q(p)=10-p, c=2, p f=8, \delta=0.5)$ 
Table 1: Descriptive Statistics for Entire First-stage Sample of Variables, 1980-1994.

\begin{tabular}{lcccc}
\hline Variables & Mean & $\begin{array}{c}\text { Standard } \\
\text { Deviation }\end{array}$ & Minimum & Maximum \\
\hline Random-effects logit estimates of petition & & & & \\
probabilities & & & & \\
& & & & \\
Dependent variable: "1"= petition, & & & & \\
"0"=no petition & 0.038 & 0.190 & 0.000 & \\
& & & & \\
Independent Variables: & & & & \\
Import penetration share lagged. & 13.484 & 15.669 & 0.000 & 95.801 \\
Import penetration share lagged and & & & & \\
$\quad$ squared. & 427.29 & 1017.78 & 0.000 & 9177.87 \\
Industry employment lagged. (in 000s) & 40.105 & 61.544 & 0.000 & 694.000 \\
Real GDP growth rate & 2.747 & 2.197 & -2.023 & 7.263 \\
Exchange rate index (1981=100) & 94.805 & 13.072 & 81.500 & 121.100 \\
Previous AD petitions. & 0.150 & 0.357 & 0.000 & 1.000
\end{tabular}

Multinomial logit estimates of case outcomes

Dependent variable: " 1 " = affirmative, "2"=negative, "3"=terminated/VER

$\begin{array}{llll}1.699 & 0.661 & 1.000 & 3.000\end{array}$

Independent Variables:

Import penetration share lagged.

Import penetration share lagged and squared.

Industry employment lagged. (in 000s)

Real GDP growth rate

Exchange rate index $(1981=100)$

Import value of investigated product.

Import value of investigated product squared.

Previous affirmative decision.

Previous negative decision.

Previous terminated/VER decision.

4-firm concentration ratio.

$\begin{array}{llll}15.076 & 8.806 & 1.027 & 66.494\end{array}$

Iron and steel products.

Steel pipe products.

$\begin{array}{cccc}304.71 & 462.64 & 1.055 & 4421.48 \\ 117.71 & 128.69 & 1.300 & 632.400 \\ 2.683 & 2.310 & -2.023 & 7.263 \\ 96.271 & 14.606 & 81.500 & 121.100 \\ 33826 & 83351 & 0.000 & 859800\end{array}$

Non-market economy.

Less-developed country.

$\begin{array}{cccc}8.08 \mathrm{E}+09 & 4.82 \mathrm{E}+10 & 0.000 & 7.39 \mathrm{E}+11 \\ 0.217 & 0.412 & 0.000 & 1.000 \\ 0.298 & 0.458 & 0.000 & 1.000 \\ 0.165 & 0.371 & 0.000 & 1.000 \\ 37.538 & 16.212 & 9.000 & 100.000 \\ 0.366 & 0.442 & 0.000 & 1.000 \\ 0.083 & 0.275 & 0.000 & 1.000 \\ 0.108 & 0.310 & 0.000 & 1.000 \\ 0.499 & 0.500 & 0.000 & 1.000 \\ 0.288 & 0.453 & 0.000 & 1.000 \\ 0.122 & 0.327 & 0.000 & 1.000 \\ 0.158 & 0.365 & 0.000 & 1.000\end{array}$


Table 2: Random-effects logit estimation of first-stage determinants of U.S. AD petition probability.

\begin{tabular}{lccc}
\hline & \multicolumn{2}{c}{ Dependent Variable: "1" if petition; "0" otherwise. } \\
\cline { 2 - 4 } Explanatory Variables & $\begin{array}{c}\text { Estimation for } \\
\mathbf{1 9 8 5} \text { (using 1980- } \\
1984 \text { data) }\end{array}$ & $\begin{array}{c}\text { Estimation for } \\
\mathbf{1 9 9} \text { (using 1980- } \\
1989 \text { data) }\end{array}$ & $\begin{array}{c}\text { Estimation for } \\
\mathbf{1 9 9 5} \text { (using 1980- } \\
1994 \text { data) }\end{array}$ \\
\hline \hline Import penetration share lagged. & & & \\
& $0.052^{*}$ & $0.073^{* * *}$ & $0.093^{* * *}$ \\
Import penetration lagged and squared. & $(0.031)$ & $(0.023)$ & $(0.022)$ \\
& -0.001 & $-0.001^{* * *}$ & $-0.002^{* * *}$ \\
Industry employment lagged. & $(0.001)$ & $(0.0005)$ & $(0.0005)$ \\
& $0.005^{* * *}$ & $0.005^{* * *}$ & $0.005^{* * *}$ \\
Real GDP growth rate & $(0.001)$ & $(0.001)$ & $(0.001)$ \\
& -0.040 & $-0.065^{*}$ & $-0.061^{*}$ \\
Exchange rate index (1981=100) & $(0.047)$ & $(0.036)$ & $(0.033)$ \\
& -0.014 & & $0.022^{* * *}$ \\
Previous AD petitions & $(0.017)$ & $(0.007)$ & $(0.006)$ \\
Chi-squared statistic & $2.506^{* * *}$ & $1.653^{* * *}$ & $1.105^{* * *}$ \\
Number of observations & $(0.285)$ & $(0.305)$ & $(0.294)$ \\
NOTES: Standard & & $109.85^{* * *}$ & $86.73^{* * *}$ \\
& $129.99 * * *$ & 4324 & 6471 \\
\hline
\end{tabular}

NOTES: Standard errors are in parentheses, with ***,** and $*$ denoting statistical significance (two-tailed test) at the 1, 5 and 10 percent levels, respectively. 
Table 3: Multinomial logit estimation of first-stage determinants of U.S. AD case outcome probabilities.

\begin{tabular}{|c|c|c|c|}
\hline \multirow[b]{2}{*}{ Explanatory Variables } & \multicolumn{3}{|c|}{$\begin{array}{c}\text { Dependent Variable: } \\
\text { "1" if affirmative; "2" if negative; "3" if terminated/VER }\end{array}$} \\
\hline & $\begin{array}{c}\text { Estimation for } \\
\mathbf{1 9 8 5} \text { (using 1980- } \\
1984 \text { data) }\end{array}$ & $\begin{array}{l}\text { Estimation for } \\
\mathbf{1 9 9 0} \text { (using 1980- } \\
1989 \text { data) }\end{array}$ & $\begin{array}{c}\text { Estimation for } \\
1995 \text { (using } 198 \\
1994 \text { data) }\end{array}$ \\
\hline \multicolumn{4}{|l|}{ Determinants of affirmative outcomes } \\
\hline Industry import penetration share & -0.089 & -0.060 & $-0.087 * *$ \\
\hline lagged. & $(0.064)$ & $(0.041)$ & $(0.030)$ \\
\hline $\begin{array}{l}\text { Industry import penetration lagged and } \\
\text { squared. }\end{array}$ & $\begin{array}{c}0.002 \\
(0.001)\end{array}$ & $\begin{array}{c}0.001 \\
(0.001)\end{array}$ & $\begin{array}{l}0.002 * * * \\
(0.001)\end{array}$ \\
\hline Industry employment lagged. & $\begin{array}{c}0.001 \\
(0.002)\end{array}$ & $\begin{array}{c}0.002 \\
(0.002)\end{array}$ & $\begin{array}{l}0.0002 \\
(0.001)\end{array}$ \\
\hline Real GDP growth rate & $\begin{array}{c}0.051 \\
(0.078)\end{array}$ & $\begin{array}{l}0.050 \\
(0.055)\end{array}$ & $\begin{array}{l}0.119^{* * *} \\
(0.045)\end{array}$ \\
\hline Exchange rate index $(1981=100)$ & $\begin{array}{l}0.0003 \\
(0.030)\end{array}$ & $\begin{array}{c}-0.005 \\
(0.011)\end{array}$ & $\begin{array}{r}-0.014^{*} \\
(0.007)\end{array}$ \\
\hline Import value of investigated product & $\begin{array}{l}-6.30 \mathrm{e}-07 \\
(9.46 \mathrm{e}-06)\end{array}$ & $\begin{array}{l}4.44 \mathrm{e}-06 \\
(4.11 \mathrm{e}-06)\end{array}$ & $\begin{array}{l}6.13 \mathrm{e}-06^{* *} \\
(2.83 \mathrm{e}-06)\end{array}$ \\
\hline $\begin{array}{l}\text { Import value of investigated product } \\
\text { squared }\end{array}$ & $\begin{array}{c}2.57 \mathrm{e}-12 \\
(3.68 \mathrm{e}-11)\end{array}$ & $\begin{array}{l}-5.30 \mathrm{e}-12 \\
(7.37 \mathrm{e}-12)\end{array}$ & $\begin{array}{c}-7.71 \mathrm{e}-12^{*} \\
(4.59 \mathrm{e}-12)\end{array}$ \\
\hline $\begin{array}{l}\text { Previous affirmative decision in } \\
\text { investigated product }\end{array}$ & $\begin{array}{c}-1.127 \\
(1.379)\end{array}$ & $\begin{array}{l}1.848^{* * *} \\
(0.520)\end{array}$ & $\begin{array}{l}0.820^{* * *} \\
(0.313)\end{array}$ \\
\hline $\begin{array}{l}\text { Previous negative decision in } \\
\text { investigated product }\end{array}$ & $\begin{array}{r}-0.097 \\
(0.802)\end{array}$ & $\begin{array}{l}-0.037 \\
(0.404)\end{array}$ & $\begin{array}{l}-0.638^{* *} \\
(0.292)\end{array}$ \\
\hline $\begin{array}{l}\text { Previous terminated/suspended decision } \\
\text { in investigated product }\end{array}$ & $\begin{array}{r}-0.509 \\
(1.083)\end{array}$ & $\begin{array}{l}-1.536^{* *} \\
(0.612)\end{array}$ & $\begin{array}{l}-1.021 * * * \\
(0.385)\end{array}$ \\
\hline Industry 4-firm concentration ratio & $\begin{array}{r}-0.024 \\
(0.014)\end{array}$ & $\begin{array}{l}-0.011 \\
(0.007)\end{array}$ & $\begin{aligned}-0.009 \\
(0.006)\end{aligned}$ \\
\hline Iron and steel products. & $\begin{array}{c}0.702 \\
(0.944)\end{array}$ & $\begin{array}{l}-0.356 \\
(0.626)\end{array}$ & $\begin{array}{l}0.578 \\
(0.379)\end{array}$ \\
\hline Steel pipe products & $\begin{array}{r}1.001 \\
(0.899)\end{array}$ & $\begin{array}{r}0.428 \\
(0.528)\end{array}$ & $\begin{array}{l}1.139 * * * \\
(0.397)\end{array}$ \\
\hline Non-market economy & $\begin{array}{c}0.595 \\
(0.925)\end{array}$ & $\begin{array}{c}0.722 \\
(0.550)\end{array}$ & $\begin{array}{l}0.886^{* *} \\
(0.357)\end{array}$ \\
\hline Less-developed country & $\begin{array}{r}1.464^{*} \\
(0.768)\end{array}$ & $\begin{array}{c}0.676 \\
(0.429)\end{array}$ & $\begin{array}{c}0.625^{*} \\
(0.323)\end{array}$ \\
\hline European union & $\begin{array}{c}0.551 \\
(0.648)\end{array}$ & $\begin{array}{c}0.003 \\
(0.394)\end{array}$ & $\begin{array}{c}0.254 \\
(0.314)\end{array}$ \\
\hline Japan & $\begin{array}{l}1.952^{* *} \\
(0.765)\end{array}$ & $\begin{array}{l}0.981^{* *} \\
(0.471)\end{array}$ & $\begin{array}{l}1.088^{* * *} \\
(0.378)\end{array}$ \\
\hline Asian NICs & $\begin{array}{l}-0.825 \\
(0.787)\end{array}$ & $\begin{array}{l}-0.305 \\
(0.399)\end{array}$ & $\begin{array}{l}-0.180 \\
(0.285)\end{array}$ \\
\hline
\end{tabular}

Determinants of terminated outcomes

Industry import penetration share

$\begin{array}{lcr}1.708^{* * *} & -0.058 & 0.093^{*} \\ (0.522) & (0.088) & (0.056)\end{array}$

lagged. 


\begin{tabular}{|c|c|c|c|}
\hline $\begin{array}{l}\text { Industry import penetration lagged and } \\
\text { squared. }\end{array}$ & $\begin{array}{l}-0.081 * * * \\
(0.023)\end{array}$ & $\begin{array}{l}0.0003 \\
(0.003)\end{array}$ & $\begin{array}{l}-0.002 \\
(0.001)\end{array}$ \\
\hline \multirow[t]{2}{*}{ Industry employment lagged. } & -0.005 & $0.006^{* * *}$ & $0.005 * * *$ \\
\hline & $(0.004)$ & $(0.002)$ & $(0.001)$ \\
\hline \multirow[t]{2}{*}{ Real GDP growth rate } & 0.091 & $0.153^{* *}$ & $0.127 * *$ \\
\hline & $(0.103)$ & $(0.070)$ & $(0.057)$ \\
\hline \multirow[t]{2}{*}{ Exchange rate index $(1981=100)$} & -0.003 & $0.030 *$ & $0.035 * * *$ \\
\hline & $(0.047)$ & $(0.017)$ & $(0.009)$ \\
\hline \multirow[t]{2}{*}{ Import value of investigated product } & $4.27 \mathrm{e}-05 * * *$ & $1.55 \mathrm{e}-05 * * *$ & $9.12 \mathrm{e}-06^{* *}$ \\
\hline & $(1.23 \mathrm{e}-05)$ & $(5.37 \mathrm{e}-06)$ & $(3.63 \mathrm{e}-06)$ \\
\hline \multirow{2}{*}{$\begin{array}{l}\text { Import value of investigated product } \\
\text { squared }\end{array}$} & $-6.56 \mathrm{e}-11 * *$ & $-2.05 \mathrm{e}-11^{*}$ & $-1.07 \mathrm{e}-11^{*}$ \\
\hline & $(3.17 \mathrm{e}-11)$ & $(1.07 \mathrm{e}-11)$ & $(6.30 \mathrm{e}-12)$ \\
\hline \multirow{2}{*}{$\begin{array}{l}\text { Previous affirmative decision in } \\
\text { investigated product }\end{array}$} & 1.656 & $2.196 * * *$ & $0.851^{* *}$ \\
\hline & $(1.149)$ & $(0.571)$ & $(0.393)$ \\
\hline \multirow{2}{*}{$\begin{array}{l}\text { Previous negative decision in } \\
\text { investigated product }\end{array}$} & 0.180 & -0.559 & -0.538 \\
\hline & $(0.759)$ & $(0.493)$ & $(0.371)$ \\
\hline \multirow{2}{*}{$\begin{array}{l}\text { Previous terminated/suspended decision } \\
\text { in investigated product }\end{array}$} & -0.246 & -0.590 & $-0.794 *$ \\
\hline & $(0.914)$ & $(0.532)$ & $(0.427)$ \\
\hline \multirow[t]{2}{*}{ Industry 4-firm concentration ratio } & -0.043 & $-0.033 * *$ & $-0.017 *$ \\
\hline & $(0.027)$ & $(0.016)$ & $(0.010)$ \\
\hline \multirow[t]{2}{*}{ Iron and steel products. } & $3.895^{* * *}$ & $1.369 *$ & 0.555 \\
\hline & $(1.385)$ & $(0.710)$ & $(0.442)$ \\
\hline \multirow[t]{2}{*}{ Steel pipe products } & 1.673 & $1.521 * *$ & 0.682 \\
\hline & $(1.132)$ & $(0.658)$ & $(0.513)$ \\
\hline \multirow[t]{2}{*}{ Non-market economy } & $2.215^{* *}$ & $1.149 *$ & $0.774^{*}$ \\
\hline & $(1.128)$ & $(0.618)$ & $(0.436)$ \\
\hline \multirow[t]{2}{*}{ Less-developed country } & 0.552 & $1.057 * *$ & $1.181 * * *$ \\
\hline & $(0.952)$ & $(0.531)$ & $(0.427)$ \\
\hline \multirow[t]{2}{*}{ European union } & 0.732 & $0.933 *$ & $1.043 * *$ \\
\hline & $(0.796)$ & $(0.507)$ & $(0.412)$ \\
\hline \multirow[t]{2}{*}{ Japan } & 0.170 & 0.540 & 0.149 \\
\hline & $(1.119)$ & $(0.727)$ & $(0.610)$ \\
\hline \multirow[t]{2}{*}{ Asian NICs } & $-3.042 * *$ & $-1.473 * *$ & $-1.019 * *$ \\
\hline & $(1.353)$ & $(0.640)$ & $(0.437)$ \\
\hline Chi-squared statistic & $151.88 * * *$ & $218.48 * * *$ & $229.40 * * *$ \\
\hline Pseudo $\mathrm{R}^{2}$ & 0.32 & 0.23 & 0.15 \\
\hline Number of observations & 214 & 448 & 715 \\
\hline
\end{tabular}

NOTES: Standard errors are in parentheses, with $* * * * *$ and $*$ denoting statistical significance (two-tailed test) at the 1, 5 and 10 percent levels, respectively. 
Table 4: Estimation of second-stage determinants of AD margin changes after affirmative AD outcome.

\begin{tabular}{|c|c|c|c|c|}
\hline \multirow[b]{2}{*}{ Regressors } & \multicolumn{3}{|c|}{$\begin{array}{c}\text { Tobit } \\
\text { Estimation }\end{array}$} & \multirow{2}{*}{$\begin{array}{c}\begin{array}{c}\text { Probit } \\
\text { Estimation }\end{array} \\
\text { Controls }\end{array}$} \\
\hline & No Controls & Controls & $\begin{array}{c}\text { Broader } \\
\text { Definition of } \\
\text { Term/Susp. }\end{array}$ & \\
\hline \multicolumn{5}{|l|}{ Focus Variables } \\
\hline $\begin{array}{l}\text { Ex ante probability of } \\
\text { AFFIRMATIVE outcome. }\end{array}$ & $\begin{array}{l}-0.642 \\
(0.494)\end{array}$ & $\begin{array}{l}0.802 * * \\
(0.409)\end{array}$ & $\begin{array}{l}0.716^{* *} \\
(0.340)\end{array}$ & $\begin{array}{l}2.799 * * * \\
(0.901)\end{array}$ \\
\hline $\begin{array}{l}\text { Ex ante probability of } \\
\text { TERMINATION/VER } \\
\text { outcome. }\end{array}$ & $\begin{array}{l}-3.282 * * * \\
(0.901)\end{array}$ & $\begin{array}{l}-1.716^{*} \\
(0.934)\end{array}$ & $\begin{array}{l}-0.406 \\
(0.679)\end{array}$ & $\begin{array}{l}-2.799 \\
(3.301)\end{array}$ \\
\hline \multicolumn{5}{|l|}{$\begin{array}{l}\text { Controls for DOC } \\
\text { methodology: }\end{array}$} \\
\hline $\begin{array}{l}\text { Change from BIA to no } \\
\text { BIA. }\end{array}$ & & $\begin{array}{l}0.108^{*} \\
(0.060)\end{array}$ & $\begin{array}{r}0.116^{*} \\
(0.060)\end{array}$ & $\begin{array}{l}0.627 * * * \\
(0.137)\end{array}$ \\
\hline $\begin{array}{l}\text { Change from no BIA to } \\
\text { BIA. }\end{array}$ & & $\begin{array}{l}1.244 * * * \\
(0.127)\end{array}$ & $\begin{array}{l}1.263^{* * *} \\
(0.128)\end{array}$ & $\begin{array}{l}1.314 * * * \\
(0.402)\end{array}$ \\
\hline $\begin{array}{l}\text { Period of automatic } \\
\text { administrative reviews. }\end{array}$ & & $\begin{array}{l}-0.481 * * * \\
(0.091)\end{array}$ & $\begin{array}{l}-0.547 * * * \\
(0.093)\end{array}$ & $\begin{array}{l}-0.819^{* * *} \\
(0.198)\end{array}$ \\
\hline Non-market economy. & & $\begin{array}{c}0.138^{*} \\
(0.080)\end{array}$ & $\begin{array}{c}0.137 \\
(0.080)\end{array}$ & $\begin{array}{l}0.831 * * * \\
(0.207)\end{array}$ \\
\hline Revocation of AD duty. & & $\begin{array}{l}-1.047 * * * \\
(0.162)\end{array}$ & $\begin{array}{l}-1.107 * * * \\
(0.157)\end{array}$ & $\begin{array}{l}-1.325^{* * *} \\
(0.306)\end{array}$ \\
\hline $\begin{array}{l}\text { Chi-squared statistic. } \\
\text { Pseudo R }{ }^{2} \text {. } \\
\text { Number of observations. }\end{array}$ & $\begin{array}{l}64.59 * * * \\
0.05 \\
541\end{array}$ & $\begin{array}{l}260.12^{* * *} \\
0.22 \\
541\end{array}$ & $\begin{array}{c}249.92^{* * *} \\
0.21 \\
541\end{array}$ & $\begin{array}{c}152.97 * * * \\
0.21 \\
541\end{array}$ \\
\hline
\end{tabular}

NOTES: Dependent variable for tobit estimation is the 4-year percentage change in the AD duty, while the dependent variable for the probit estimation a dummy variable that takes the value of "1" if AD duty does not decrease. Robust standard errors for all variables except the ex ante probabilities, for which the standard errors are bootstrapped. $* * *, * *$ and $*$ denote statistical significance (two-tailed test) at the 1,5 and 10 percent levels, respectively. 